\title{
A DYNAMIC MODEL OF FOOD AND CLEAN ENERGY
}

\author{
by
}

Ujjayant Chakravorty $^{1}$, Bertrand Magné $^{2}$ and Michel Moreaux ${ }^{3}$

\begin{abstract}
In the midwestern United States, ethanol produced from corn is mixed with gasoline to meet clean air standards. Allocating land to produce clean fuel means taking away land from farming. We examine a model in which a scarce fossil fuel (e.g., oil) causes pollution but may be substituted by a clean fuel produced from land. Methodologically, we extend the Hotelling model to consider a substitute produced in the agricultural sector. We discover a range of prices within which the land-based fuel may substitute for the fossil fuel. When land is abundant, the supply of the clean fuel may exhibit multiple discontinuities. Environmental regulation may cause food production and farm prices to remain constant for a period of time.
\end{abstract}

JEL classification: Q41, Q42, Q15

Keywords: Agriculture, Environmental regulation, Hotelling theory, Land use, Pollution

\footnotetext{
${ }^{1}$ Corresponding Author: Department of Economics, University of Central Florida, Orlando, FL 32816,USA and University of Toulouse, phone: 407823 4728, fax 407823 3269, uchakravorty@bus.ucf.edu.

${ }^{2}$ University of Toulouse I (CEA, LERNA), 21 Allée de Brienne, 31000 Toulouse, France;

${ }^{3}$ University of Toulouse I (IUF, IDEI and LERNA), 21 Allée de Brienne, 31000 Toulouse, France.
} 


\section{Introduction}

The Ford Motor Company has introduced several types of Flexible Fuel Vehicles (FFVs) that run on E85, a mixture of 85\% ethanol (made from corn) and 15\% gasoline. There are 3.5 million FFVs already plying on US highways but only 400 fuelling stations that supply E85. A bill passed by the US Senate provides tax credits for building E85 fueling stations. After the bill's passage, United States Sen. Barrack Obama said: “a fuel made of 85 percent Midwestern corn is a lot more desirable than one made from 100 percent Middle Eastern Oil.”

The US Environmental Protection Agency is considering regulating a renewable energy standard, by which a designated fraction of all gasoline must come from renewable energy sources such as ethanol. These trends towards meeting clean energy goals through fuels produced from land imply an increased competition for scarce land resources, especially in agriculture. Policy makers in the US Midwest, for example are already worried about the effect of rising ethanol consumption for energy on food prices (The New York Times, 2006). ${ }^{4}$

In this paper, we develop a dynamic model that examines this trade-off between producing clean energy and using land for food production. The clean energy substitutes for a polluting nonrenewable resource such as oil. We derive an equivalence between Ricardian land rent and the Hotelling rent for the nonrenewable resource. We show that the price of the clean fuel produced from land must lie within precise bounds dictated by the amount of available land and the demands for food and energy. These bounds determine the trigger price at which the land fuel is used for energy and the price at which the nonrenewable resource is completely exhausted. Supply of the land based fuel may occur in a discontinuous fashion when land is relatively abundant. Ricardian rents to land as well as Hotelling rents to oil may increase over time.

We examine how environmental regulation imposed in the form of a limit on the stock of pollution may affect the substitution to a land-based fuel. Unlike abatement technologies which

\footnotetext{
4 "High oil prices are dragging corn prices up with them, as the value of ethanol is pushed up by the value of the fuel it replaces,” The New York Times (2006).
} 
may be used only when regulation is binding, the land-based fuel may be deployed before the pollution stock is binding or later in time when pollution is no longer an issue.

There is a large literature on nonrenewable resources and pollution, including Forster (1980), Sinclair (1994), Ulph and Ulph (1994), Farzin (1996), Hoel and Kverndokk (1996), Tahvonen (1997) and Toman and Withagen (2000). The focus of these studies has largely been on the time path of pollution and carbon taxes. Hoel (1984) examines a model in which a nonrenewable resource has a perfect substitute in some of its uses but no substitute in others. He notes that resource prices may jump at the time when the substitute production comes into play. The focus of his paper is on market structure and price discrimination, not on the relationship between land and energy use. Chakravorty, Magne and Moreaux (2006) extend a Hotelling model to explore the allocation of a polluting nonrenewable resource and a clean backstop. This paper is an extension of their approach, in which we explicitly model land allocation in an agricultural sector that may produce both food and clean energy. The land endowment and magnitude of demands for food and energy affect substitution between the fossil fuel and the land fuel. On the other hand, pollution regulation in the energy sector affects the allocation of land in food production. In general, the main contribution of this paper in the literature following Hotelling (1931) is in explicitly linking the use of a nonrenewable resource over time to the allocation of land.

Section 2 outlines the basic dynamic model with land. In section 3 we develop intuition by examining polar cases of the model in which land is allocated for food alone, for both food and fuel after oil is completely depleted, and finally when both food and both sources of energy are produced. In section 4, we integrate this land market equilibrium with the dynamic equilibrium in the oil market. In section 5, we impose environmental regulation and consider when costly pollution control technologies may be deployed. Section 6 concludes the paper.

\section{The Model}

We consider an economy in which utility $U$ at any given time $t$ is produced from food and energy, denoted respectively by $q_{f}$ and $q_{e} \cdot{ }^{5}$ Utility is additive and given by the sub-utility

\footnotetext{
${ }^{5}$ In order to prevent notational clutter, we avoid writing the time argument explicitly wherever possible.
} 
functions $U=u_{f}+u_{e}$. We further assume that $u_{i}, i \in\{f, e\}: R_{+} \rightarrow R$ is of class $C^{2}$, strictly increasing and strictly concave, satisfying the Inada conditions $\lim _{q_{i} \downarrow+\infty} u_{i}^{\prime}\left(q_{i}\right)=+\infty$, where $u_{i}^{\prime}\left(q_{i}\right)=\frac{d u_{i}}{d q_{i}}$. Under these assumptions, the second derivative $u_{i}^{\prime \prime}\left(q_{i}\right) \equiv \frac{d^{2} u_{i}}{d q_{i}^{2}}$ is negative. Denote by $p_{i}$ the marginal surplus function and by $d_{i}$ its inverse, i.e., $d_{i}\left(p_{i}\right) \equiv p_{i}^{-1}\left(q_{i}\right) \equiv u^{-1^{\prime}}\left(p_{i}\right)$.

There are two primary factors, land and a fossil fuel which we call oil. Land is assumed to be homogenous in quality, and its endowment is denoted by $\bar{L}$. It can be used to produce food or an energy crop such as corn that when converted to ethanol, serves as a clean substitute for oil. ${ }^{6}$ Let $L_{i}, i \in\{f, y\}$, be the portion of land dedicated to producing food and energy, respectively. Then the residual land $\bar{L}-L_{f}-L_{y} \geq 0$ is fallow. Denote by $\bar{f}$ and $\bar{y}$ the yield of food and the land-based fuel per unit land which is assumed fixed. Their production at any instant of time is given by $f(t)=\bar{f} L_{f}$ and $y(t)=\bar{y} L_{y}$. The cost of inputs per unit land area is denoted by $c_{i}, i \in\{f, y\}$. These costs may include the cost of conversion of grain to ethanol. We assume that they do not vary with the volume of food or land fuel produced. The average cost per unit output is then given by $c_{f} / \bar{f}$ and $c_{y} / \bar{y}$ respectively. These commodities are not storable, except at a prohibitive cost.

Energy can also be produced by using oil. Let $X(0)$ be its initial stock, $X(t)$ the residual stock at time $t$ and $x(t)$ its rate of consumption so that $\dot{X}(t)=-x(t)$. Let $c_{x}$ be its average $\operatorname{cost}^{7}$ assumed to be constant and lower than the unit cost of the land fuel, $c_{x}<c_{y} / \bar{y}$. The land fuel and fossil fuel are assumed to be perfect substitutes in final demand so that the total consumption of energy at time $t$ is equal to the sum of their extraction rates: $q_{e}(t)=y(t)+x(t) .^{8}$ The land fuel is costly

\footnotetext{
${ }^{6}$ The model may need to be significantly modified to consider energy sources such as wood from tree production because harvests tend to be discrete in time.

${ }^{7}$ including the cost of extraction, processing and delivery.

${ }^{8}$ Strictly speaking, this is not an accurate depiction of E85. That would imply strict complementarity of both fuels in clean energy production, so that ethanol and oil will be produced in fixed proportions. That is, oil will be directly used in the production both fossil and clean energy. As will be clear later, such an extension will make the model complicated but may not yield many fresh insights. Both oil and ethanol production must go down over time at
} 
and produces no emissions. Let $\theta$ be the quantity of pollution (e.g., carbon) released into the atmosphere per unit of fossil fuel consumed and $Z(t)$ be this stock at time $t$, with $Z(0)$ the initial stock. As is standard in the literature we assume that there is some natural dilution of pollution that is proportional to the stock of pollution, $Z(t)$. Let $\alpha>0$ be the natural rate of decay. To keep the model simple, we abstract from considering costly pollution abatement policies, but discuss this issue later in the paper. The dynamics of pollution is given by $\dot{Z}(t)=\theta x(t)-\alpha Z(t)$.

Let $\bar{Z}$ be the pollution stock quota exogenously imposed by say, an international agreement, so that $\bar{Z}-Z(t) \geq 0$ at any time $t$. We define $\bar{x}$ as the maximum extraction rate of oil when this constraint is tight. From $\dot{Z}(t)=0$ and $Z(t)=\bar{Z}$, we get $\bar{x}=\alpha \bar{Z} / \theta$. The objective of the social planner is to maximize net aggregate surplus discounted at some constant rate $\rho>0$. The planner allocates land for food and fuel production, and the scarce fossil fuel to solve the following problem (P):

$\underset{\left\{L_{f}, L_{y}, x\right\}}{\operatorname{Max}} \int_{0}^{+\infty}\left\{u_{f}(f)+u_{e}(x+y)-c_{f} L_{f}-c_{y} L_{y}-c_{x} x\right\} e^{-\rho t} d t$

subject to

$f(t)=\bar{f} L_{f}$

$y(t)=\bar{y} L_{y}$

$\bar{L}-L_{f}-L_{y} \geq 0, L_{y} \geq 0$,

$\dot{X}=-x, \quad X(0)=X^{0}$ given, $X \geq 0, x \geq 0$, and

$\dot{Z}=\theta x-\alpha Z, Z(0)=Z^{0}<\bar{Z}$ given, $\bar{Z}-Z \geq 0$.

constant rates until infinity. Here we implicitly assume that ethanol can be used independently of oil, which may be justified as technological improvements increase the content of ethanol to higher than the current $85 \%$ or what is 
The current value Lagrangian is:

$$
\begin{aligned}
\ell & =u_{f}(f)+u_{e}(x+y)-c_{f} L_{f}-c_{y} L_{y}-c_{x} x-\lambda x \\
& +\mu[\theta x-\alpha Z]+v[\bar{Z}-Z]+\pi\left[\bar{L}-L_{f}-L_{y}\right]+\gamma_{y} L_{y}+\gamma_{x} x
\end{aligned}
$$

and the first order conditions are:

$\frac{\partial \ell}{\partial L_{f}}=0 \quad \Leftrightarrow \quad u_{f}^{\prime}(f)=\frac{c_{f}+\pi}{\bar{f}}$

$\frac{\partial \ell}{\partial L_{y}}=0 \quad \Leftrightarrow \quad u_{e}^{\prime}(x+y)=\frac{c_{y}+\pi-\gamma_{y}}{\bar{y}}$

$\frac{\partial \ell}{\partial x}=0 \quad \Leftrightarrow \quad u_{e}^{\prime}(x+y)=c_{x}+\lambda-\theta \mu-\gamma_{x}$

together with the complementary slackness conditions:

$\gamma_{y} \geq 0, \gamma_{y} L_{y}=0$

$\gamma_{x} \geq 0, \gamma_{x} x=0$,

$\pi \geq 0, \pi\left(\bar{L}-L_{f}-L_{y}\right)=0$,

where $\gamma_{y}, \gamma_{x}$ and $\pi$ are the relevant Lagrangian multipliers. Because of the Inada assumptions, we do not need a multiplier for the condition $L_{f} \geq 0$ since it will never be binding. There will always be land under food production. The dynamics of the costate variables are determined by:

$$
\begin{aligned}
& \dot{\lambda}=\rho \lambda-\frac{\partial \ell}{\partial x} \Leftrightarrow \dot{\lambda}=\rho \lambda \Rightarrow \lambda=\lambda_{0} e^{\rho t}, \\
& \dot{\mu}=\rho \mu-\frac{\partial \ell}{\partial Z} \Leftrightarrow \dot{\mu}=(\rho+\alpha) \mu+v \text {, and }
\end{aligned}
$$


$v \geq 0$, and $v[\bar{Z}-Z\rfloor=0$

where $\lambda_{0}=\lambda(0)$. The costate variable $\mu$ is non-positive. If $Z<\bar{Z}$ over some time interval $\left[t_{0}, t_{1}\right]$, then $v=0$ and $\mu(t)=\mu\left(t_{0}\right) e^{(\rho+\alpha)\left(t-t_{0}\right)}, t \in\left[t_{0}, t_{1}\right]$. Lastly, the transversality conditions at infinity are:

$\lim _{t \uparrow+\infty} e^{-\rho t} \lambda(t) X(t)=\lambda_{0} \lim _{t \uparrow+\infty} X(t)=0$,

$\lim _{t \uparrow+\infty} e^{-\rho t} \mu(t) Z(t)=0$.

We will use the term "full marginal cost" to mean the monetary cost of a good augmented by the relevant shadow price. The full marginal costs are $\frac{c_{f}+\pi}{\bar{f}}$ for food, $\frac{c_{y}+\pi}{\bar{y}}$ for the land fuel, and $c_{x}+\lambda-\theta \mu$ for oil.

\section{Land Allocation between Competing Uses}

In this section we determine optimal land use and the supply of food and energy. To develop intuition, we first examine two polar cases: (i) land is used only for food production and (ii) land is used for food and energy when oil is completely exhausted. Finally we consider the general case when land is used both for food and energy, in which the latter may be supplied by oil and the land fuel simultaneously.

\section{Land is Used only for Food}

Define $L_{f}^{f} \leq \bar{L}$ as the land parcel under food production if no energy is being produced from land. We use the superscript $f$ to denote equilibrium values in this food only model. Then the remaining land $\bar{L}-L_{f}^{f} \geq 0$ will be fallow. Let $\pi^{f}$ be the corresponding rent to land. Then $\pi_{f}\left(L_{f}\right)=\bar{f} u_{f}^{\prime}\left(\bar{f} L_{f}\right)-c_{f}$. If $\pi_{f}(\bar{L})>0$, all the land must be in use, so that $L_{f}^{f}=\bar{L}$. When land is abundant or demand for food is low, $L_{f}^{f}$ solves $\bar{f} u_{f}^{\prime}\left(\bar{f} L_{f}\right)-c_{f}=0$ and equilibrium land rent $\pi^{f}$ is 
zero. We will ignore the degenerate case in which rents go to zero exactly when all available land is used. We assume that if $\pi^{f}=0$, then $L_{f}^{f}<\bar{L}$, some land is always left fallow.

Define $p_{y}^{f}$ as the full marginal cost of the land fuel when land rents equal $\pi^{f}$, i.e., $p_{y}^{f} \equiv\left(c_{y}+\pi^{f}\right) / \bar{y}$. Then $p_{y}^{f} \geq c_{y} / \bar{y}$. If the price of energy is less than $p_{y}^{f}$, land is more productive in food production. Hence no clean fuel will be produced and only oil must be used for energy. The price $p_{y}^{f}$ thus serves as a lower bound for the price of energy at which land fuel production becomes competitive. If $\pi^{f}$ is zero, then $p_{y}^{f}=c_{y} / \bar{y}$. The trigger price for the land fuel is its average cost.

The choice of $L_{f}^{f}$ is shown in Fig.1. The function $\pi_{f}^{1}$ corresponds to a situation of low marginal product or high marginal cost in which some land is left fallow, and $\pi_{f}^{2}$ represents the case in which all land is used in food production.

\section{[Figure 1 here]}

\section{Land Use when Oil is Exhausted}

When oil is exhausted, only the land fuel must supply energy. Let $L_{f}^{y}$ and $L_{y}^{y}$ be land parcels allocated for the production of food and fuel, and $\pi^{y}$ the corresponding equilibrium land rent, where the superscript ' $y$ ' denotes equilibrium values for this model. With no oil, pollution is a non-issue since emissions are zero. The maximization problem $(\mathrm{P})$ reduces to:

$\underset{\left\{L_{f}, L_{y}\right\}}{\operatorname{Max}} \int_{0}^{+\infty}\left\{u_{f}(f)+u_{e}(y)-c_{f} L_{f}-c_{y} L_{y}\right\} e^{-\rho t} d t$

subject to

$f(t)=\bar{f} L_{f}, y(t)=\bar{y} L_{y}, \bar{L}-L_{f}-L_{y} \geq 0$ and $L_{y} \geq 0$. 
The necessary and the complementary slackness conditions are:

$$
\begin{aligned}
& \bar{f} u_{f}^{\prime}(f)=c_{f}+\pi, \\
& \overline{\mathrm{y}} u_{e}^{\prime}(y)=c_{y}+\pi-\gamma_{y}, \\
& \pi \geq 0 \text { and } \pi\left(L-L_{f}-L_{y}\right)=0, \gamma_{y} \geq 0 \text { and } \gamma_{y} L_{y}=0 .
\end{aligned}
$$

With no stock dynamics, (P1) is a static problem. Under the Inada conditions, $L_{f}^{y}>0$ and when oil is exhausted, the land fuel must supply energy so that $L_{y}^{y}>0$ and $\gamma_{y}=0$. Let $\pi_{y}\left(L_{y}\right)$ be the rent to land allocated for land fuel production, i.e. $\pi_{y}\left(L_{y}\right)=\bar{y} u_{y}^{\prime}\left(\bar{y} L_{y}\right)-c_{y}$. All the available land will be used for food and energy production if equilibrium land rents are equal and strictly positive, i.e., $\pi_{f}\left(L_{f}\right)=\pi_{y}\left(\bar{L}-L_{f}\right)>0$. This is shown in Fig. 2, in which the equilibrium rent $\pi^{y}$ is strictly positive. When land is abundant or demands are small, each marginal product may be zero, i.e., $L_{f}^{y}$ solves $\pi_{f}\left(L_{f}\right)=0$ and $L_{f}^{y}=L_{f}^{f}$. In this case land allocated for food is exactly the same as in the previous model with no energy production, and $L_{y}^{y}$ solves $\pi_{y}\left(L_{y}\right)=0$, with $L_{f}^{y}+L_{y}^{y}<\bar{L}$ and the common land rent $\pi^{y}=0$. Some land is left fallow. If equilibrium land rents are zero in the model with the land fuel, it can not be strictly positive in the food only case when there is no competition for land. That is, we can not have $\pi^{y}=0$ and $\pi^{f}>0$.

\section{[Figure 2 here]}

\section{Land Use for Food and Energy when Oil is Available}

We now consider land allocation when oil is still available. Define $p_{y}^{y}$ as the full marginal cost of the clean fuel when the land rent is equal to $\pi^{y}$, i.e., $p_{y}^{y} \equiv \frac{c_{y}+\pi^{y}}{\bar{y}}$. Rents must be higher in the presence of competing uses, hence $\pi^{y} \geq \pi^{f}$. This implies that $p_{y}^{y} \geq p_{y}^{f} \geq \frac{c_{y}}{\bar{y}}$. We then have 
$p_{y}^{f}>\frac{c_{y}}{\bar{y}}$ if $\pi^{f}>0$ and $p_{y}^{y}>p_{y}^{f}$ if $\pi^{y}>\pi^{f}$. We will see below that the price of energy is at most equal to $p_{y}^{y}$, the highest price reached once oil is exhausted. If rents are zero both in the food only and food and land fuel only models, $\pi^{y}=\pi^{f}=0$, then some land must be fallow, i.e., $L_{y}^{y}+L_{f}^{y}<\bar{L}$. ${ }^{9}$ In the food only model, there is no competition for land, hence rents will achieve some lower bound, while in the model with no oil, all energy must come from the land fuel, hence rents achieve some upper bound.

Consider energy supply for given energy prices $p_{e} \leq p_{y}^{y}$. Define $\hat{\pi}\left(p_{e}\right)$ as the land rent for which the full marginal cost of the land fuel is equal to the price of energy $p_{e}$. This price must be at least equal to the unit cost of the land fuel, $c_{y} / \bar{y}$ :

$\hat{\pi}\left(p_{e}\right)=\left\{\begin{array}{lll}0 & , & p_{e} \leq c_{y} / \bar{y} \\ \bar{y} p_{e}-c_{y} & , & c_{y} / \bar{y}<p_{e} \leq p_{y}^{y}\end{array}\right.$

Below we examine three possible cases: $\pi^{f}>0 ; \pi^{f}=0$ and $\pi^{y}>0$ and finally, $\pi^{f}=\pi^{y}=0$.

(a) All Available Land is Used under Food Production, $\pi^{f}>0$ :

When $\pi^{f}>0$, the demand for food is high or the endowment of land is low. Then $c_{y} / \bar{y}<p_{y}^{f} \leq p_{y}^{y}$. For energy prices $p_{e}<p_{y}^{f}$, we have $\hat{\pi}\left(p_{e}\right)<\pi^{f}$. Since the rent under food production is higher than in fuel production, all the available land must be used to grow food and there will be no land fuel supplied to augment the use of oil. For higher energy prices $p_{e} \in\left\lfloor p_{y}^{f}, p_{y}^{y}\right\rfloor$, we have $\hat{\pi}\left(p_{e}\right)>\pi^{f}$. The land fuel is competitive in the allocation of land, hence $y>0$ and $\gamma_{y}=0$. Equalisation of land rents implies

$$
\bar{f} u_{p_{e}}^{\prime}\left(\bar{f} L_{f}\right)-c_{f}=\bar{y} p_{e}-c_{y}
$$

\footnotetext{
${ }^{9}$ We neglect the degenerate case when $\pi^{y}=\pi^{f}=0$ and $L_{y}^{y}+L_{f}^{y}=\bar{L}$.
} 
so that

$\frac{d L_{f}}{d p_{e}}=\frac{\bar{y}}{\bar{f}^{2} u^{\prime \prime}\left(\bar{f} L_{f}\right)}<0$

A higher price of energy induces a decrease in the land allocated to food and because $L_{y}=\bar{L}-L_{f}$, an increase in the land allocated to fuel. Let $\hat{L}_{f}\left(p_{e}\right)$ be the solution to (12) for $p_{e} \in\left[p_{y}^{f}, p_{y}^{y}\right\rfloor$ and equal zero for $p_{e} \leq p_{y}^{f}$. Then the supply of landfuel as a function of $p_{e}$ given by $\hat{y}\left(p_{e}\right)$, is

$\hat{y}\left(p_{e}\right)=\bar{y}\left[\bar{L}-\hat{L}_{f}\left(p_{e}\right)\right]$.

Let the portion of energy supplied by oil be denoted by $d_{x}\left(p_{e}\right)$. It must equal the aggregate demand for energy net the quantity supplied by the land fuel, $d_{e}\left(p_{e}\right)-\hat{y}\left(p_{e}\right)$. To see that $d_{x}\left(p_{e}\right) \geq 0$, note that because $\pi^{f}>0$, when $p_{e}=p_{y}^{f}$, we have $d_{x}\left(p_{y}^{f}\right)>0$ and $\hat{y}\left(p_{y}^{f}\right)=0$ and when $p_{e}=p_{y}^{y}, d_{e}\left(p_{y}^{y}\right)=\hat{y}\left(p_{y}^{y}\right)$. Since $d_{e}\left(p_{e}\right)$ is decreasing while $\hat{y}\left(p_{e}\right)$ is increasing we conclude that $d_{x}\left(p_{e}\right) \geq 0$ and $d_{x}\left(p_{e}\right)$ must be decreasing from $d_{e}\left(p_{y}^{f}\right)$ at $p_{e}=p_{y}^{f}$ down to zero at $p_{e}=p_{y}^{y}$. Furthermore $d_{x}\left(p_{e}\right)$ is continuous at $p_{e}=p_{y}^{f}$ although nondifferentiable. The derived demand function for oil, $d_{x}\left(p_{e}\right)$ is illustrated in Fig. 3

\section{[Figure 3 here]}

(b) Land is Fallow under Food Production but not for both Food and Energy, $\pi^{f}=0, \pi^{y}>0$ : This case may arise if there is enough land for food production but not for producing both food and energy. Or if the demand for food is low relative to the demand for energy. The land rent under food production is zero, but not when both food and energy are being produced after the exhaustion of oil. Then $p_{y}^{f}=c_{y} / \bar{y}$ and $p_{y}^{y}>p_{y}^{f}=c_{y} / \bar{y}>c_{x}$. This case was illustrated in Fig. 2 
where the trigger price for land fuel is the unit cost of production $c_{y} / \bar{y}$. At prices $p_{e}>p_{y}^{f}=c_{y} / \bar{y}$ a strictly positive quantity of land fuel is supplied because $\hat{\pi}_{y}\left(p_{e}\right)>\pi^{f}$. The value of $L_{f}$ that solves (12) is strictly positive and bounded from above by $L_{y}^{f}<\bar{L}$, so that $\lim _{p_{e} \downarrow c_{y} / \bar{y}}\left(\bar{L}-\hat{L}_{f}\left(p_{e}\right)\right)>0$ implies $\lim _{p_{e} \downarrow c_{y} / \bar{y}} \hat{y}\left(p_{e}\right)<d_{e}\left(p_{y}^{f}\right)$. When $p_{e}<p_{y}^{f}, \hat{y}\left(p_{e}\right)=0$. Thus at $p_{e}=c_{y} / \bar{y}, y\left(p_{e}\right)=0$ jumps from 0 to $\lim _{p_{e} \downarrow c_{y} / \bar{y}}\left(\bar{L}-\hat{L}_{f}\left(p_{e}\right)\right)=\bar{y}\left(\bar{L}-L_{f}^{f}\right)>0$. The case is illustrated in Fig. 4 below.

\section{[Figure 4 here]}

(c) Land is Abundant both for Food and Energy, $\pi^{f}=\pi^{y}=0$ :

Finally suppose land is abundant or the demand for food and energy is small. Then $p_{y}^{f}=p_{y}^{y}=c_{y} / \bar{y}$. For any price of energy $p_{e}$ that is higher than the trigger price $c_{y} / \bar{y}$, all energy has to be supplied by land and the demand for oil decreases from $d_{e}\left(c_{y} / \bar{y}\right)$ to a value that is indeterminate within the interval $\left[0, d_{e}\left(c_{y} / \bar{y}\right)\right]$. This is the case in which the land fuel acts as a pure backstop at the price $c_{y} / \bar{y}$, as shown in Fig. 5 .

\section{[Figure 5 here]}

\section{The Land Fuel in a Hotelling Model}

In this section we impose dynamics on the above Ricardian framework. First we consider the Hotelling model without any environmental regulation. This is problem (P) without the constraint $\bar{Z}-Z \geq 0$. The modified condition (3) now becomes $u^{\prime}(x+y)=c_{x}+\lambda-\gamma_{x}$ and conditions (8), (9) and (11) no longer hold.

Since $c_{x}<c_{y} / \bar{y} \leq p_{y}^{f} \leq p_{y}^{y}$, the interval $\left[c_{x}, p_{y}^{y}\right)$ is nondegenerate. For any $\lambda_{0} \in\left(0, p_{y}^{y}-c_{x}\right)$ let $p_{x}\left(\lambda_{0}\right)$ be the Hotelling price of oil which must equal the marginal extraction cost augmented by the scarcity rent of the resource, i.e., $p_{x}\left(\lambda_{0}\right)=c_{x}+\lambda_{0} e^{\rho t}$. Let $\Gamma^{y}\left(\lambda_{0}\right)$ be the time at which this 
price is equal to $p_{y}^{y}$, i.e., $\Gamma^{y}\left(\lambda_{0}\right)=\rho^{-1}\left[\ln \left(p_{y}^{y}-c_{x}\right)-\ln \lambda_{0}\right]$. Then we must have $\frac{d \Gamma^{y}}{d \lambda_{0}}>0$, $\lim _{\lambda_{0} \uparrow p_{y}^{y}-c_{x}} \Gamma^{y}=0$ and $\lim _{\lambda_{0} \downarrow 0} \Gamma^{y}=+\infty$. A higher initial Hotelling rent will shorten the date of exhaustion of oil.

Let $X\left(\lambda_{0}\right)$ be the cumulative consumption of oil over the time interval $\left[0, \Gamma^{y}\left(\lambda_{0}\right)\right]$ along this Hotelling price path. The aggregate supply of oil is $\left.X\left(\lambda_{0}\right)=\int_{0}^{\Gamma^{y}} d_{x}\left(\lambda_{x}\right)\left(\lambda_{0}\right)\right) d t$. We have $\frac{d X}{d \lambda_{0}}<0$, $\lim _{\lambda_{0} \uparrow p_{y}^{y}-c_{x}} X=0$ and $\lim _{\lambda_{0} \downarrow 0} X=+\infty$ which suggests that the equation $X\left(\lambda_{0}\right)=X^{0}$ has a unique solution given by the optimal value of the Hotelling rent of oil, absent environmental regulation. As a function of $X^{0}$, the equilibrium rent is decreasing with $\lim _{X_{0} \uparrow_{\infty}} \lambda_{0}=0$ and $\lim _{X^{0} \downarrow 0} \lambda_{0}=p_{y}^{y}-c_{x}$.

Let $x\left(\lambda_{0}\right)$ and $y\left(\lambda_{0}\right)$ denote the oil and land fuel consumption paths corresponding to the Hotelling price path $p_{x}\left(\lambda_{0}\right)$. For $\lambda_{0} \in\left(0, p_{y}^{f}-c_{x}\right)$, define $\Gamma^{f}\left(\lambda_{0}\right)$ as the time at which $p_{x}\left(\lambda_{0}\right)=p_{y}^{f}$, that is $\Gamma^{f}\left(\lambda_{0}\right)=\rho^{-1}\left[\ln \left(p_{y}^{f}-c_{x}\right)-\ln \lambda_{0}\right]$. Then for $\pi^{y}>0$, that includes the two cases $\pi^{y}>\pi^{f}>0$ and $\pi^{y}>\pi^{f}=0$, if $\lambda_{0} \in\left(0, p_{y}^{f}-c_{x}\right)$, we have

$$
\begin{aligned}
& x\left(\lambda_{0}\right)=\left\{\begin{array}{ccc}
d_{x}\left(p_{x}\left(\lambda_{0}\right)\right)=d_{e}\left(p_{x}\left(\lambda_{0}\right)\right) & , & 0 \leq t<\Gamma^{f}\left(\lambda_{0}\right) \\
d_{x}\left(p_{x}\left(\lambda_{0}\right)\right)<d_{e}\left(p_{x}\left(\lambda_{0}\right)\right) & , & \Gamma^{f}\left(\lambda_{0}\right)<t<\Gamma^{y}\left(\lambda_{0}\right), \\
0 & , & \Gamma^{y}\left(\lambda_{0}\right) \leq t
\end{array}\right. \\
& y\left(\lambda_{0}\right)=\left\{\begin{array}{ccc}
0 & 0 \leq t<\Gamma^{f}\left(\lambda_{0}\right) \\
d_{e}\left(p_{e}\left(\lambda_{0}\right)\right)-d_{x}\left(p_{e}\left(\lambda_{0}\right)\right) & , & \Gamma^{f}\left(\lambda_{0}\right)<t<\Gamma^{y}\left(\lambda_{0}\right) \\
y^{y} & , & \Gamma^{y}\left(\lambda_{0}\right) \leq t
\end{array}\right.
\end{aligned}
$$

where $y^{y}=\bar{y} L_{y}^{y}$. For $\lambda_{0} \in\left(p_{y}^{f}-c_{x}, p_{y}^{y}-c_{x}\right)$, the phase during which oil supplies all energy consumption disappears. The unit cost of the land fuel is lower than the full marginal cost of oil. When $\pi^{f}>0$, the case shown in Fig. 3, oil supplies all the energy until the Hotelling price equals 
the trigger price $p_{y}^{f}$. Above this price, the supply of oil is augmented by fuel from land. The supply of the land fuel increases until oil is completely exhausted at price $p_{y}^{y}$, as shown in Fig. 6 . When $\pi^{f}=0$ but $\pi^{y}>0$, the supply of the land fuel is as shown in Fig.4. Oil supply is positive in the entire price range $\left(p_{y}^{f}, p_{y}^{y}\right)$. Oil is exhausted when the price reaches $p_{y}^{y}$. Finally, when $\pi^{y}=0$, then $p_{y}^{y}=p_{y}^{f}=c_{y} / \bar{y}$, the land fuel acts as a pure backstop resource. Only oil is supplied until time $\Gamma^{f}=\Gamma^{y}$, shown in Fig. 7. The intermediate phase of simultaneous extraction that occurred previously disappears.

\section{[Figures 6 and 7 here]}

\section{Use of the Clean Energy under Environmental Regulation}

Consider a cap on the stock of emissions. This constraint can be relaxed either by reducing the use of oil, supplying energy from land or by costly pollution abatement. The land fuel is more costly than oil, and supplying it reduces the consumption of food when land is scarce. We first examine a model with no pollution abatement.

We distinguish between the solution values of the variables in the model absent any regulation and the model with regulation. Let $\lambda_{0}^{H}$ be the optimal scarcity rent in the regulation free model. Then $Z^{H}\left(\lambda_{0}^{H}\right)$ is the time path of the pollution stock induced by oil extraction rate $x\left(\lambda_{0}^{H}\right)$ when the initial stock is $Z^{0}$ and there is no pollution cap. ${ }^{10}$ We assume that the ceiling constraint is binding along this standard Hotelling path. Beyond $\Gamma^{y}\left(\lambda_{0}^{H}\right)$, no fossil fuel is used and $Z^{H}$ falls smoothly to zero. The binding constraint may be stated as $\operatorname{Max}\left\{Z^{H}\left(\lambda_{0}^{H}\right), t \in\left[0, \Gamma^{y}\left(\lambda_{0}^{H}\right)\right]\right\} \leq \bar{Z}$.

${ }^{10}$ Formally $Z^{H}$ solves the differential equation $\frac{d Z^{H}}{d t}=\theta x\left(\lambda_{0}^{H}\right)-\alpha Z^{H}\left(\lambda_{0}^{H}\right), Z_{0}^{H}=Z^{0}$. For $\lambda_{0}^{H}<p_{y}^{f}-c_{x}$, the extraction rate $x\left(\lambda_{0}^{H}\right)$ is not differentiable (is discontinuous) at time $\Gamma^{f}$ when the price of oil is $p_{y}^{f}$ and $\pi^{f}>0$ $(=0)$. Then we must first solve this differential equation over the time interval $\left[0, \Gamma^{f}\left(\lambda_{0}^{H}\right)\right)$. Let $Z_{\Gamma^{f}\left(\lambda_{0}^{H}\right)}^{\text {be the }}$ limit of $Z^{H}$ as $t \uparrow \Gamma^{f}\left(\lambda_{0}^{H}\right)$. Next solve the same equation over the time interval $\left[\Gamma^{f}\left(\lambda_{0}^{H}\right), \infty\right)$ taking $Z_{\Gamma^{f}}^{H}$ as 
If $\bar{\tau}$ is the final instant of time at which the constraint is tight, then $\mu(t)=0$ beyond time $\bar{\tau}$. Beyond $\bar{\tau}$ the environmental constraint no longer binds and resources are allocated as in a Hotelling model. Let $\underline{\tau}$ be the first time instant at which the ceiling constraint is binding ( $Z^{0}<\bar{Z}$ implies $\underline{\tau}>0$ ). Over the time interval $[0, \underline{\tau})$ the constraint is not binding but will later in time. Since $\bar{Z}-Z>0$ then $v=0$ so that $\mu=\mu_{0} e^{(\rho+\alpha) t}$ with $\mu_{0}<0$ and the full cost of the fossil fuel is denoted by $\breve{p}_{e}$ such that $\breve{p}_{e}\left(\lambda_{0}, \mu_{0}\right)=c_{x}+\lambda_{0} e^{\rho t}-\mu_{0} e^{(\rho+\alpha) t}$. Let $\breve{Z}\left(\lambda_{0}, \mu_{0}\right)$ be the path of the stock of pollution corresponding to the price path $\breve{p}_{e}\left(\lambda_{0}, \mu_{0}\right)$, i.e., the path defined by

$$
\frac{d \breve{Z}}{d t}=\theta d_{x}\left(\breve{p}_{e}\left(\lambda_{0}, \mu_{0}\right)\right)-\alpha \breve{Z}, \breve{Z}_{0}=Z^{0}
$$

The land fuel may be economically feasible according to whether the constrained oil extraction at the ceiling $\bar{x}(=\alpha \bar{Z} / \theta)$ is higher or lower than demand at the trigger price given by $d_{e}\left(p_{y}^{f}\right)$. The intuition is that if $\bar{x}>d_{e}\left(p_{y}^{f}\right)$, then the constraint is not tight enough or the opportunity cost of the land fuel is relatively high so that using land to provide supplementary clean energy in order to satisfy the constraint is cost prohibitive. In other words, the price at which the consumption of oil is constrained is lower than the lowest opportunity cost of the land fuel $p_{y}^{f}$. We re-examine the three cases discussed earlier from the point of view of environmental regulation:

(a) All Available Land is Used under Food Production, $\pi^{f}>0$ : Here $p_{y}^{y}>p_{y}^{f}>c_{y} / \bar{y}>c_{x}$ and the demand for oil $d_{x}$ is continuous at the trigger price $p_{y}^{f}$. The price $\bar{p}_{e}$ at which $d_{x}\left(p_{e}\right)=\bar{x}$ is well defined. If $\bar{p}_{e}>p_{y}^{f}$, as shown in Fig. 8, the land fuel is competitive at prices $p_{e} \in\left(p_{y}^{f}, \bar{p}_{e}\right)$. It is used along with oil before regulation becomes binding. Both fuels are also used at the ceiling. There is an initial phase during which the stock is lower than the ceiling and the price of fuel is given by $\breve{p}_{e}\left(\lambda_{0}, \mu_{0}\right)$. This phase may include a segment

the initial condition and $\lim _{p_{e} \downarrow p_{y}^{f}} d_{x}\left(p_{e}\right)$ as the initial demand. The path $Z^{H}$ is continuous at time $t=\Gamma^{f}\left(\lambda_{0}^{H}\right)$ but 
during which both fuels are used simultaneously. At time $t=0, \breve{p}_{e}\left(\lambda_{0}, \mu_{0}\right)<p_{y}^{f}$, as shown in the figure. If $\breve{p}_{e}\left(\lambda_{0}, \mu_{0}\right)>p_{y}^{f}$ then both fuels must be used from the beginning. During this initial phase the pollution stock $\breve{Z}$ is increasing. The ceiling is attained at time $\underline{\tau}$ at which $\breve{Z}\left(\lambda_{0}, \mu_{0}\right)=\bar{Z}$ and $\breve{p}_{e}\left(\lambda_{0}, \mu_{0}\right)=\bar{p}_{e}$.

At the ceiling, the price of fuel is constant at $\bar{p}_{e}$. Oil consumption is constrained at $\bar{x}$ and land fuel consumption is given by $y=d_{e}\left(\bar{p}_{e}\right)-d_{x}\left(\bar{p}_{e}\right)>0$. During this time $\mu$ is increasing, i.e., decreasing in absolute value. At the end of this phase at $t=\bar{\tau}$, pollution is no longer an issue and $\mu=0$ for the rest of the planning horizon. The next phase is a pure Hotelling phase during which $p_{e}=p_{x}\left(\lambda_{0}\right)$. Oil consumption is decreasing but land fuel supply is increasing in response to the rise in prices. At time $t=\Gamma^{y}\left(\lambda_{0}\right)$, oil is exhausted. Beyond this time, the land fuel is the only source of energy. ${ }^{11}$

\section{[Figure 8 here]}

Before the land fuel is produced, land is allocated only for food. When supply of the land fuel begins, land allocated to food production declines until the pollution stock hits the ceiling. At the ceiling, the supply of the clean fuel is constant, hence food production and prices are also constant. Once the ceiling is no longer constrained, food production continues to decline until it reaches a steady state at $t=\Gamma^{y}\left(\lambda_{0}\right)$. Environmental regulation leads to constant food output and prices for a time period. If there was no regulation, the decline in food production would be gradual until oil was exhausted and land fuel supply was at its maximum level.

When the price at the ceiling is lower than the minimum price at which land fuels become economical, only oil is consumed at the ceiling and the land fuel is supplied after the ceiling period is completed. ${ }^{12}$

\footnotetext{
not differentiable.

${ }^{11}$ See Appendix A for technical details of this solution.

${ }^{12}$ For reasons of space, this case is not illustrated in the paper.
} 
(b) Land is Fallow under Food Production but not for both Food and Energy, $\pi^{f}=0, \pi^{y}>0$ : In this case if $\bar{x}<\lim _{p_{e} \downarrow p_{y}^{f}} d_{x}\left(p_{e}\right)$, then $\bar{p}_{e}>p_{y}^{f}$, so the land fuel is used at the ceiling. But if $\bar{x}>d_{e}\left(p_{y}^{f}\right)$, then $\bar{p}_{e}<p_{y}^{f}$ and the clean fuel is used only in the post-ceiling period. However, if $\lim _{p_{e} \downarrow p_{y}^{f}} d_{x}\left(p_{e}\right)<\bar{x}<d_{e}\left(p_{y}^{f}\right)$ and $d_{x}\left(p_{y}^{f}\right)$ is not well defined at $p_{e}=p_{y}^{f}$, there is a jump discontinuity when the energy price equals $p_{y}^{f}$. As shown in Fig. 9, at the end of the first phase oil consumption is discontinuous and falls from $d_{e}\left(p_{y}^{f}\right)$ to $\bar{x}$. The deficit is supplied by land fuel. There is no impact on food production because aggregate production of the land fuel is less than what available land can produce, given by $d_{e}\left(p_{y}^{f}\right)-\lim _{p_{e} \downarrow p_{y}^{f}} d_{x}\left(p_{e}\right)$. Part of the land is fallow from the beginning until time $\bar{\tau}$ when oil consumption falls again from $\bar{x}$ to $\lim _{p_{e} \downarrow p_{y}^{f}} d_{x}\left(p_{e}\right)$ and clean fuel consumption jumps up by the same amount. The land constraint now becomes binding. Oil is exhausted and the supply of the land fuel increases to $y^{y}$, with aggregate energy consumption declining due to the increase in the price of energy. Food consumption decreases from $f^{f}$ to $f^{y} .{ }^{13}$ There are two jumps in the supply of the clean fuel, at time $\underline{\tau}$ and $\bar{\tau}$.

(c) Land is Abundant both for Food and Energy, $\pi^{f}=\pi^{y}=0$ :

The analysis is the same as before except when $d_{x}\left(p_{e}\right)=0$ for $p_{e}>p_{y}^{f}=p_{y}^{y}$. See Fig. 10 for the case $\bar{x}<d_{e}\left(p_{y}^{f}\right)$. Supply of the land fuel starts exactly at the ceiling and there is no Hotelling phase after the ceiling. Oil supply exhibits a discontinuity from $d_{e}\left(p_{y}^{f}\right)$ to $\bar{x}$. The difference is supplied by the clean fuel but all available land is not utilized. Oil is exhausted exactly at

\footnotetext{
${ }^{13}$ The optimal values of $\lambda_{0}, \mu_{0}, \underline{\tau}, \bar{\tau}$ and $\Gamma^{y}$ are determined as in the previous case. The cumulative consumption/supply balance equation of the fossil fuel can be written as$$
\int_{0}^{\tau} d_{e}\left(\breve{p}_{e}\left(\lambda_{0}, \mu_{0}\right)\right) d t+\bar{x}[\bar{\tau}-\tau]+\int_{\bar{\tau}}^{\Gamma^{y}} d_{x}\left(p_{x}\left(\lambda_{0}\right)\right) d t=X^{0} .
$$ 
time $\bar{\tau}$ when the land fuel supply jumps up from $d_{e}\left(p_{y}^{f}\right)-\bar{x}$ to $d_{e}\left(p_{y}^{f}\right)=y^{f}$, which lasts until infinity. ${ }^{14}$

\section{[Figure 10 here]}

The clean fuel may work as a textbook backstop resource and may not supplement the fossil fuel, as illustrated in Fig. 11 where $\bar{x}>d_{e}\left(p_{e}^{f}\right)=d_{e}\left(c_{y} / \bar{y}\right)$. Define $\bar{p}_{e}$ as the price at which $d_{e}\left(p_{e}\right)=\bar{x}$. At time $\Gamma^{y}$, oil is exhausted, its consumption falling from $d_{x}\left(p_{y}^{f}\right)=d_{e}\left(c_{y} / \bar{y}\right)$ to zero and is completely replaced by the land fuel.

\section{[Figure 11 here]}

\section{The Clean Fuel and Costly Pollution Control}

In this section, we investigate the relationship between using land to produce clean energy and alternative pollution control policies such as through more efficient appliances (e.g., scrubbers). We focus only on the intuition. ${ }^{15}$ Suppose the stock of pollution can be reduced through costly abatement, denoted by $a$. The average abatement cost, denoted by $c_{a}$, is assumed constant. Then the total instantaneous abatement cost is equal to $c_{a} a$ and the new dynamics of the pollution stock is given by $\dot{Z}=\theta x-a-\alpha Z$. With abatement, the new maximum extraction rate of oil at the ceiling will be $\bar{x}(a)$ where $\bar{x}(a)=(a+\alpha \bar{Z}) / \theta$. When $a=0$, we get back the original extraction rate $\bar{x}$. The optimization program (P) must now be modified by including abatement $a$ as a choice variable. This new program (P2) yields the following additional conditions:

\footnotetext{
${ }^{14}$ This solution is characterized by the values of the variables $\lambda_{0}, \mu_{0}, \underline{\tau}$ and $\bar{\tau}$ that solve the following system of four equations: the cumulated demand/supply balance equation $\int_{0}^{\tau} d_{e}\left(\breve{p}_{e}\left(\lambda_{0}, \mu_{0}\right)\right) d t+\bar{x}[\bar{\tau}-\underline{\tau}]=X^{0}$; the pollution stock continuity equation at $\underline{\tau}: \breve{Z}\left(\lambda_{0}, \mu_{0}\right)=\bar{Z}$; the price continuity equations at $\underline{\tau}, \bar{\tau}$ : $\breve{p}_{e}\left(\lambda_{0}, \mu_{0}\right)=p_{y}^{f}\left(=p_{y}^{y}=c_{y} / \bar{y}\right)$ at $t=\underline{\tau}$ and $p_{x}\left(\lambda_{0}\right)=p_{y}^{f}\left(=p_{y}^{y}=c_{y} / \bar{y}\right)$ at $t=\bar{\tau}$.

15 Technical details are provided in Appendix B.
} 
$\frac{\partial \ell}{\partial a}=0 \Leftrightarrow-\mu=c_{a}-\gamma_{a}$

$\gamma_{a} \geq 0$ and $\gamma_{a} a=0$,

where $\gamma_{a}$ is a Lagrangian multiplier. Define $\tilde{p}_{e}\left(\lambda_{0}\right)$ as the full marginal cost of the clean fossil fuel including the marginal cost of abatement but excluding the shadow cost of the ceiling constraint: $\tilde{p}_{e}\left(\lambda_{0}\right)=c_{x}+\lambda_{0} e^{\rho t}+\theta c_{a}$. Abatement will not occur if the full marginal cost with abatement is higher than the one with no abatement. There is no benefit from abating when the stock of pollution is strictly below the ceiling. Suppose, abatement occurs at time $t<\underline{\tau}$, before attaining the ceiling. Then $\mu=\mu_{0} e^{(\rho+\alpha) t}, t \in[0, \underline{\tau})$. Since $a>0, t \in[0, \underline{\tau})$, then $\gamma_{a}=0$ over this interval. Together with (15) this implies that $-\mu=c_{a}$. Both $\mu(t)=\mu_{0} e^{(\rho+\alpha) t}$ and $\mu=-c_{a}$, $t \in[0, \underline{\tau})$ cannot be true, hence we arrive at a contradiction. Abatement must occur only at the ceiling. Abatement is costly and reducing pollution when the constraint is not binding confers no additional benefit.

Abatement must also occur only at the beginning of the ceiling period, if at all. By definition, the marginal cost of oil under abatement $\tilde{p}_{e}\left(\lambda_{0}\right)$ is upward sloping, since it depends upon the price of oil. If abatement were optimal, then this graph must cut the horizontal ceiling price $\bar{p}_{e}$ at some time period, say $\tilde{\tau}$. Before this time, the abatement marginal cost is below $\bar{p}_{e}$ hence abatement is economical, and after $\tilde{\tau}$, the marginal cost is above $\bar{p}_{e}$, hence abatement becomes too expensive. Given that the unit cost of pollution control is constant and the ceiling is tight, the earlier it is done the better, since that allows increased use of cheap oil earlier in time.

In summary, there is a clear distinction between the two options for pollution reduction. Abatement may happen only at the ceiling and must commence at the beginning. The use of the land fuel may start before the ceiling, and once energy production from land begins, it will always be part of the fuel mix. This is because the scarcity of oil drives the price of oil higher, making the land fuel relatively cheaper over time. The land fuel may be supplied starting from before the ceiling is binding, interior to the ceiling or after the ceiling no longer holds. 


\section{Concluding Remarks}

In this paper we develop a Hotelling model with a market for land that drives the supply of clean energy. We discover a range of energy prices within which the land-based fuel may substitute for the fossil fuel. Depending on whether land is abundant and the magnitude of demands for food and energy, the supply of the land fuel may occur discontinuously, and before or after environmental regulation is binding. Regulation causes the price of energy to increase, therefore more land is allocated away from food production. However, if the demand for energy is high, then regulation forces food production and prices to remain constant over an extended time period.

The proposed framework can be used to make informed predictions on how agricultural policies may affect the supply of clean energy from land that substitutes for a non-renewable resource such as oil in transportation. Policies that decrease the demand for food will lead to an increase in the supply of the clean energy. These may include the removal of export subsidies on the domestic agricultural sector and import tariffs for agricultural products. Technological change in food production (e.g., introduction of high-yielding varieties) that increases profits per unit of land will lead to a substitution of land away from energy into food production and a consequent increase in the price of energy. In the other direction, environmental policies in the energy sector may also affect the land market equilibrium. If demand for energy were to increase and then decline exogenously, because of changes in population and economic growth, the land fuel may be supplied in an initial period and then the economy may switch back to oil, leading to an increase in food production and a decrease in the price of food. There may be a period in the interim when food production goes to zero and all land is used to produce energy, with the bulk of agriculture shifting into imports. However domestic production may come back if energy demand declines in the future. In an international context, environmental regulation in developed economies may cause an increase in food prices, leading to increased imports from developing countries. Domestically, there may be a shift in land use from other sectors into the production of food and energy.

In future work it may be important to consider Ricardian land with differential quality. The 
scarcity of land may drive up food and energy prices, which in turn may determine equilibrium land qualities in each sector as well as technological progress in these sectors, assumed constant in this model. In a global economy, differential land qualities and demands may dictate the optimal allocation of food production as well as land-based pollution control activities such as sequestration through forestry. 


\section{References}

Chakravorty, U., B. Magne and M. Moreaux (2006), “A Hotelling Model with a Ceiling on the Stock of Pollution,” forthcoming, Journal of Economic Dynamics and Control.

Farzin, Y.H. (1996), “Optimal Pricing of Environmental and Natural Resource Use with Stock Externalities,” Journal of Public Economics (62), 31-57.

Forster, B.A., (1980), Optimal Energy Use in a Polluted Environment, Journal of Environmental Economics and Management (7), 321-33.

Hoel, M., (1984), "Extraction of a Resource with a Substitute for Some of its Uses," Canadian Journal of Economics (17), 593-602.

Hoel, M., and S. Kverndokk (1996), Depletion of Fossil Fuels and the Impacts of Global Warming,” Resource and Energy Economics (18), 115-36.

Hotelling, H., (1931), “The Economics of Exhaustible Resources,” Journal of Political Economy 39(2), $137-75$.

Ricardo, D., (1917), Principles of Political Economy and Taxation, Prometheus Books.

Sinclair, P., (1994), “On the Optimal Trend of Fossil Fuel Taxation,” Oxford Economic Papers (46), 85768.

Tahvonen, O., (1997), “Fossil Fuels, Stock Externalities and Backstop Technologies,” Canadian Journal of Economics (30), 855-74.

The New York Times (2006), "Corn Farmers Smile as Ethanol Prices Rise, but Experts on Food Supplies Worry,” by Matthew L. Wald, January 16.

Toman, M.A., and C. Withagen (2000), “Accumulative Pollution, Clean Technology and Policy Design,” Resource and Energy Economics, (22), 367-84.

Ulph, A., and D. Ulph (1994), “The Optimal Time Path of a Carbon Tax,” Oxford Economic Papers (46), 857-68. 


\section{Appendix A}

We determine the values of the two rents $\lambda_{0}$ and $\mu_{0}$ and the three dates $\underline{\tau}, \bar{\tau}$ and $\Gamma^{y}\left(\lambda_{0}\right)$ that solve the following five equations system: the cumulative demand/supply balance for oil,

$\int_{0}^{\underline{\tau}} d_{x}\left(c_{x}+\lambda_{0} e^{\rho t}-\theta \mu_{0} e^{(\rho+\alpha) t}\right) d t+x[\bar{\tau}-\underline{\tau}]+\int_{\bar{\tau}}^{\Gamma^{y}\left(\lambda_{0}\right)} d_{x}\left(c_{x}+\lambda_{0} e^{\rho t}\right) d t=X^{0} ;$ the pollution stock

continuity equation at $\underline{\tau}, \breve{Z}\left(\lambda_{0}, \mu_{0}\right)=\bar{Z}$; the price continuity equations at $\underline{\tau}, \bar{\tau}$ and $\Gamma^{y}$ :

$\breve{p}_{e}\left(\lambda_{0}, \mu_{0}\right)=\bar{p}_{e}$ at $t=\underline{\tau}, p_{x}\left(\lambda_{0}\right)=p_{y}^{f}$ at $t=\bar{\tau}$, and $p_{x}\left(\lambda_{0}\right)=p_{y}^{y}$ at $t=\Gamma^{y}\left(\lambda_{0}\right)$. For any set of solution values for these variables $\lambda_{0}, \mu_{0}, \underline{\tau}, \bar{\tau}$ and $\Gamma^{y}\left(\lambda_{0}\right)$, there exists values of the multipliers such that all the first order conditions are satisfied by:

$$
\begin{aligned}
& x(t)=\left\{\begin{array}{lll}
d_{x}\left(\breve{p}_{e}\left(\lambda_{0}, \mu_{0}\right)\right) & , \quad 0 \leq t<\underline{\tau} \\
\bar{x}\left(p_{x}\left(\lambda_{0}\right)\right) & , \quad \underline{\tau}<t<\bar{\tau} \\
d_{x}, & \bar{\tau} \leq t<\Gamma^{y}\left(\lambda_{0}\right) \\
0 & , & \Gamma^{y}\left(\lambda_{0}\right) \leq t
\end{array}\right. \\
& y(t)=\left\{\begin{array}{lll}
d_{e}\left(\breve{p}_{e}\left(\lambda_{0}, \mu_{0}\right)\right)-d_{x}\left(\breve{p}_{e}\left(\lambda_{0}, \mu_{0}\right)\right) & , \quad 0 \leq t<\underline{\tau} \\
d_{e}\left(\bar{p}_{e}\right)-\bar{x} & , \quad \underline{\tau}<t<\bar{\tau} \\
d_{e}\left(p_{x}\left(\lambda_{0}\right)\right)-d_{x}\left(p_{x}\left(\lambda_{0}\right)\right) \quad & \bar{\tau} \leq t<\Gamma^{y}\left(\lambda_{0}\right) \\
d_{e}\left(p_{e}^{y}\right) & \Gamma^{y}\left(\lambda_{0}\right) \leq t
\end{array}\right. \\
& q_{f}(t)=\left\{\begin{array}{lll}
\hat{q}_{f}\left(\breve{p}_{e}\left(\lambda_{0}, \mu_{0}\right)\right) & , \quad 0 \leq t<\underline{\tau} \\
\hat{q}_{f}\left(\bar{p}_{e}\right) & , \quad \underline{\tau}<t<\bar{\tau} \\
\hat{q}_{f}\left(p_{x}\left(\lambda_{0}\right)\right) & , & \bar{\tau} \leq t<\Gamma^{y}\left(\lambda_{0}\right) \\
\hat{q}_{f}\left(p_{y}^{y}\right) & , & \Gamma^{y}\left(\lambda_{0}\right) \leq t
\end{array}\right.
\end{aligned}
$$

where $\hat{q}_{f}\left(p_{e}\right)$ is optimal food production for a given energy price $p_{e}$, i.e., $\hat{q}_{f}\left(p_{e}\right) \equiv \bar{f} \hat{L}_{f}\left(p_{e}\right)$. It is easy to check that the nonnegative functions $\gamma_{x}, \gamma_{y}, \pi,-\mu$ and $v$ satisfy the necessary conditions (1)-(11).

$\gamma_{x}= \begin{cases}0 & , 0 \leq t \leq \Gamma^{y} \\ p_{x}\left(\lambda_{0}\right)-p_{y}^{y} & , \quad \Gamma^{y} \leq t\end{cases}$ 


$$
\begin{aligned}
& \gamma_{y}= \begin{cases}\breve{p}_{e}\left(\lambda_{0}, \mu_{0}\right) \bar{y}-c_{y}-\pi^{f} & , 0 \leq t \leq \Gamma^{f}\left(\lambda_{0}\right) \\
0 & , \quad \Gamma^{f}\left(\lambda_{0}\right) \leq t\end{cases} \\
& \pi= \begin{cases}\pi^{f} & , \quad 0 \leq t \leq \Gamma^{f}\left(\lambda_{0}\right) \\
\hat{\pi}\left(p_{e}\right) & , \quad \Gamma^{f}\left(\lambda_{0}\right) \leq t \leq \Gamma^{y}\left(\lambda_{0}\right) \\
\pi^{y} & , \quad \Gamma^{y}\left(\lambda_{0}\right) \leq t\end{cases} \\
& \mu= \begin{cases}\mu_{0} e^{(\rho+\alpha) t} & , \quad 0 \leq t \leq \underline{\tau} \\
-\left(\bar{p}_{e}-p_{x}\right) / \theta & , \quad \underline{\tau} \leq t \leq \bar{\tau}, \text { and } \\
0 & , \quad \bar{\tau} \leq t\end{cases}
\end{aligned}
$$

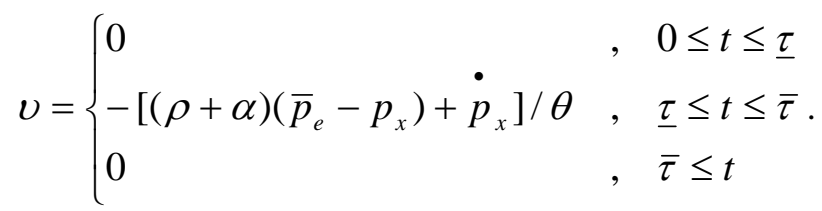

\section{Appendix B}

\section{Checking the optimality of an active abatement policy}

Let the subscript $n a$ (no abatement) denote equilibrium values in the model with no abatement, where the variables are denoted by $\lambda_{0}^{n a}, \mu_{0}^{n a}$ and $\underline{\tau}^{n a}$. Let $\tilde{p}_{e}^{n a}$ denote the function $\tilde{p}_{e}\left(\lambda_{0}\right)$ and $\breve{p}_{e}^{n a}$ the function $\breve{p}_{e}\left(\lambda_{0}, \mu_{0}\right)$, for $\lambda_{0}^{n a}$ and $\mu_{0}^{n a}$. The no abatement policy is optimal if and only if $\widetilde{p}_{e}^{n a} \geq \breve{p}_{e}^{n a}, t \geq 0$. In the initial phase before the ceiling with $x>0$, the price path $p_{e}^{n a}$ is given by $\breve{p}_{e}^{n a}$ until time $t=\underline{\tau}^{n a}$, followed by a period when the ceiling is constrained during which $p_{e}^{n a}$ is constant and equal to either $\bar{p}_{e}$ or $p_{y}^{f}$, and there may exist a third phase with $p_{e}^{n a}$ as the Hotelling path with $p_{e}^{n a}=p_{x}^{n a}=\tilde{p}^{n a}-c_{a}{ }^{16}$

\footnotetext{
${ }^{16}$ The condition $p_{e}^{n a}=c_{x}+\lambda_{0}^{n a} e^{\rho t}-\theta \mu^{n a}$ always holds although the value of $\mu^{\text {na }}$ may change from one phase to another.
} 
Let $\tilde{p}_{e}^{n a}<\breve{p}_{e}^{n a}$ over some time interval that includes $\underline{\tau}$, say $\left(\underline{\tau}^{n a}-\varepsilon_{1}, \underline{\tau}^{n a}+\varepsilon_{2}\right), \varepsilon_{i}>0, i=1,2$. Assume it is optimal not to abate and consider the interval during which $p_{e}^{n a}=\breve{p}^{n a}$. Since $x>0$, then by (15), and $\gamma_{a} \geq 0$, we have $c_{a} \geq-\mu$ so that $\tilde{p}_{e}^{n a} \geq \breve{p}_{e}^{\text {na }}$, which is a contradiction. Thus it is optimal to abate.

However, consider the case when $\widetilde{p}_{e}^{n a} \geq \breve{p}_{e}^{n a}, t \geq 0$. At any time $t$ such that $x>0, \gamma_{a}=0, \tilde{p}_{e}^{n a}>p_{e}^{n a}$ which implies $c_{a}>-\mu_{t}$. By (15), $c_{a}=-\mu+\gamma_{a}$ and the preceding inequalities hold if and only if $\gamma_{a}>0$, i.e., if and only if $a=0$. Thus it is optimal not to abate. The constrained solution with no abatement is indeed the first best solution. In this case, the graph of $\widetilde{p}_{e}^{n a}$ shifts up and cuts the graph of $\breve{p}_{e}^{n a}$ beyond time $\underline{\tau}^{n a}$.

Determining the characteristics of the optimal path

Assume it is optimal to abate. We may have different scenarios according to the values of $p_{y}^{f}, p_{y}^{y}$ and $\bar{p}_{e}$, one of which is illustrated in Fig B1. $\underline{\tau}$ is the time at which the ceiling begins to be active and abatement begins, $\delta$ the time at which the abatement must end and $\bar{\tau}$ the time at which the ceiling constraint ceases to be active.

\section{[Figure B1 here]}

We need to solve for $\lambda_{0}, \mu_{0}, \underline{\tau}, \delta, \bar{\tau}$ and $\Gamma^{y}$ from the following system of six equations: the cumulative demand/supply balance equation for oil given by $\int_{0}^{\delta} d_{x}\left(\breve{p}_{e}\left(\lambda_{0}, \mu_{0}\right)\right) d t+[\bar{\tau}-\delta] \bar{x}+\int_{\bar{\tau}}^{\Gamma_{x}^{y}} d_{x}\left(p_{x}\left(\lambda_{0}\right)\right) d t=X^{0}$; the pollution stock continuity equation at $\underline{\tau}$, the time at which the ceiling is attained, $\breve{Z}\left(\lambda_{0}, \mu_{0}\right)=\bar{Z}$; the price continuity equations - at time $\underline{\tau}$ : $\breve{p}_{e}\left(\lambda_{0}, \mu_{0}\right)=\tilde{p}_{e}\left(\lambda_{0}\right)$; time $\delta: \tilde{p}_{e}\left(\lambda_{0}\right)=\bar{p}_{e}$; time $\bar{\tau}: p_{x}\left(\lambda_{0}\right)=\bar{p}_{e}$ and time $\Gamma^{y}: p_{x}\left(\lambda_{0}\right)=p_{y}^{y}$.

In Fig. B1 we assume that $p_{y}^{f}<\bar{p}_{e}$ and that $p_{y}^{f}$ is lower than $\breve{p}\left(\lambda_{0}, \mu_{0}\right)$ at time $\underline{\tau}$. We denote by $t^{b}$ the time at which $\breve{p}\left(\lambda_{0}, \mu_{0}\right)=p_{y}^{f}$. Hence the ceiling constraint is first relaxed by both pollution abatement 
and use of the land fuel followed only by the latter. But for a higher trigger price $p_{y}^{f}$, still lower than $\bar{p}_{e}$, we could have three phases at the ceiling: first abatement, next abatement and use of land fuel and finally use of the land fuel only. For $p_{y}^{f}>\bar{p}_{e}$, the only option is to abate.

\section{List of Symbols}

U: utility function or gross surplus, $U \equiv u_{f}+u_{e}$

$u_{i}\left(q_{i}\right), i \in\{f, e\}:$ gross surplus generated by good $i$

$u_{i}^{\prime}\left(q_{i}\right)$ denoted by $p_{i}, i \in\{f, e\}$

$\bar{L}$ : land endowment

$L_{i}, i \in\{f, y\}:$ land allocated to good $i, \bar{L}-L_{f}-L_{y} \geq 0$

$y$ : quantity of land fuel

$\bar{f}, \bar{y}$ : yields per unit of land, $q_{f}=\bar{f} L_{f}, y=\bar{y} L_{y}$

$c_{f}, c_{y}:$ cost per unit of land

$c_{f} / \bar{f}, c_{y} / \bar{y}:$ cost per unit output

$X$ : stock of fossil fuel, $X^{0}$ initial stock

$x(t)$ : extraction rate of fossil fuel

$q_{e}=y+x$

$\pi$ : land rent

$\lambda$ : scarcity rent of oil, $\lambda_{0}$ : initial value, $\lambda=\lambda_{0} e^{\rho t}$

$Z$ : stock of pollutant

$\bar{Z}$ : pollution cap: $\bar{Z}-Z(t) \geq 0$

$\theta$ : pollution per unit of fossil fuel

$a$ : abatement

$\alpha$ : natural regeneration rate of pollution

$\dot{Z}=\theta x-\alpha Z, Z(0)=Z^{0}<\bar{Z}$ given, $\bar{Z}-Z \geq 0$

$\bar{x}(a)=(a+\alpha \bar{Z}) / \theta:$ constrained oil consumption when $Z=\bar{Z}, \bar{x} \equiv \bar{x}(0)$ 
$\mu$ : shadow cost of the pollutant stock, $\mu_{0}$ initial value

$C_{a}$ : unit cost of abatement

$p_{x}\left(\lambda_{0}\right)=c_{x}+\lambda_{0} e^{\rho t}$

$\tilde{p}_{e}\left(\lambda_{0}\right)=c_{x}+\lambda_{0} e^{\rho t}+\theta c_{a}$

$\breve{p}_{e}\left(\lambda_{0}, \mu_{0}\right)=c_{x}+\lambda_{0} e^{\rho t}-\mu_{0} e^{(\rho+\alpha) t}$

If land is allocated only to food production, then

$L_{f}^{f}$ : land allocated to food production

$\pi^{f}$ : land rent

$p_{y}^{f} \equiv\left(c_{y}+\pi^{f}\right) / \bar{y}$ : full marginal cost of land fuel for $\pi=\pi^{f}$

If land is allocated to both food and fuel production, then

$L_{f}^{y}, L_{y}^{y}:$ land allocated to food and fuel, respectively

$\pi^{y}$ : land rent

$p_{y}^{y} \equiv\left(c_{y}+\pi^{y}\right) / \bar{y}$ : full marginal cost of land fuel for $\pi=\pi^{y}$

$\pi_{f}\left(L_{f}\right) \equiv \bar{f} u_{f}^{\prime}\left(\bar{f} L_{f}\right)-c_{f}$ : land rent for land under food production

$\pi_{y}\left(L_{y}\right) \equiv \bar{y} u_{y}^{\prime}\left(\bar{y} L_{y}\right)-c_{y}$ : land rent for land under fuel production, absent fossil fuel

$\Gamma^{f}\left(\lambda_{0}\right)=\rho^{-1}\left[\ln \left(p_{y}^{f}-c_{x}\right)-\ln \lambda_{0}\right]$, defined for $\lambda_{0} \in\left(0, p_{y}^{f}-c_{x}\right)$

$\Gamma^{y}\left(\lambda_{0}\right)=\rho^{-1}\left[\ln \left(p_{y}^{y}-c_{x}\right)-\ln \lambda_{0}\right]$, defined for $\lambda_{0} \in\left(0, p_{y}^{y}-c_{x}\right)$

For a given price of energy $p_{e}$,

$\hat{L}_{f}\left(p_{e}\right), \hat{L}_{y}\left(p_{e}\right)$ : land allocation when rents are equal for food and fuel

$\hat{\pi}\left(p_{e}\right)$ : land rent

$\hat{y}\left(p_{e}\right)=\bar{y} \hat{L}_{y}\left(p_{e}\right):$ output of land fuel

$\hat{q}_{f}\left(p_{e}\right)=\bar{f} \hat{L}_{f}\left(p_{e}\right):$ output of food

$d_{x}\left(p_{e}\right) \equiv d_{e}\left(p_{e}\right)-\hat{y}\left(p_{e}\right):$ residual demand for oil

$x\left(\lambda_{0}\right)$ : oil consumption along path $p_{x}\left(\lambda_{0}\right)=x\left(\lambda_{0}\right) \equiv d_{x}\left(p_{x}\left(\lambda_{0}\right)\right)$

$y\left(\lambda_{0}\right)$ : oil consumption along path $p_{x}\left(\lambda_{0}\right): y\left(\lambda_{0}\right) \equiv \bar{y} \hat{L}_{f}\left(p_{x}\left(\lambda_{0}\right)\right)$ 


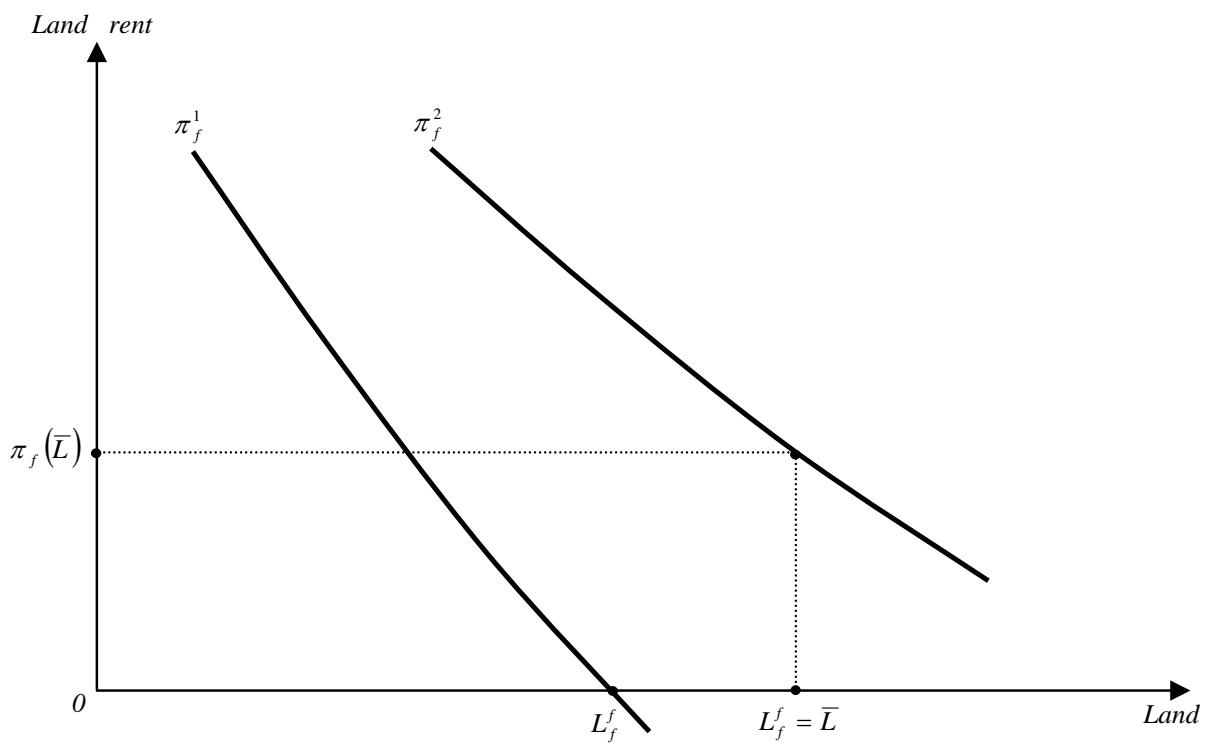

Fig 1. Land is used only for Food

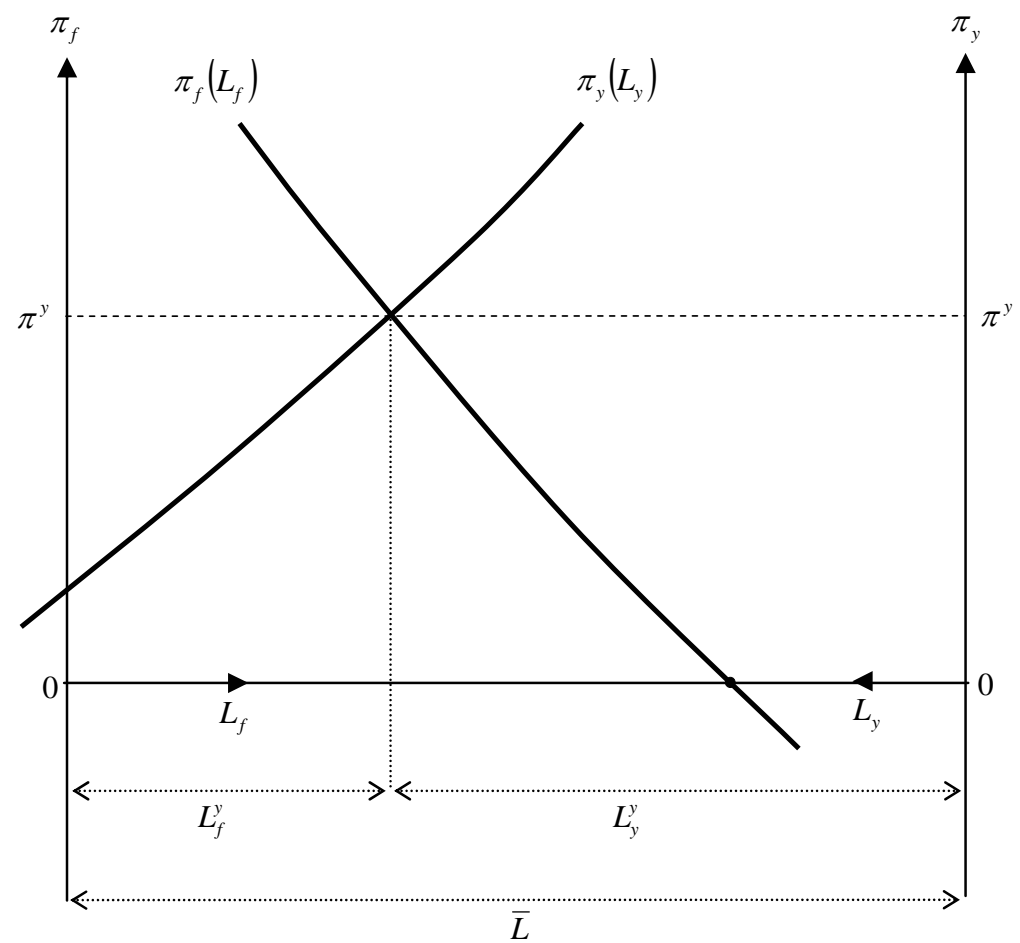

Fig 2. Land is used both for Food and Clean Energy 


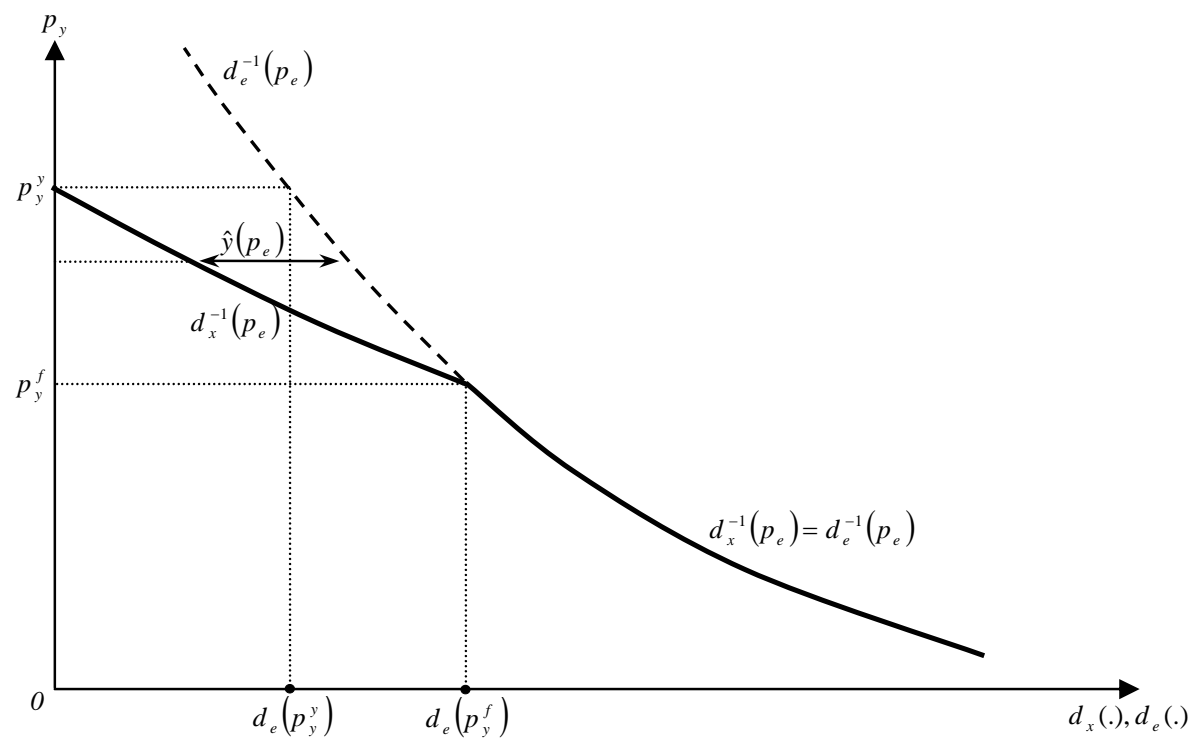

Fig 3. Energy Supply when Land is Scarce or Demand for Food is High

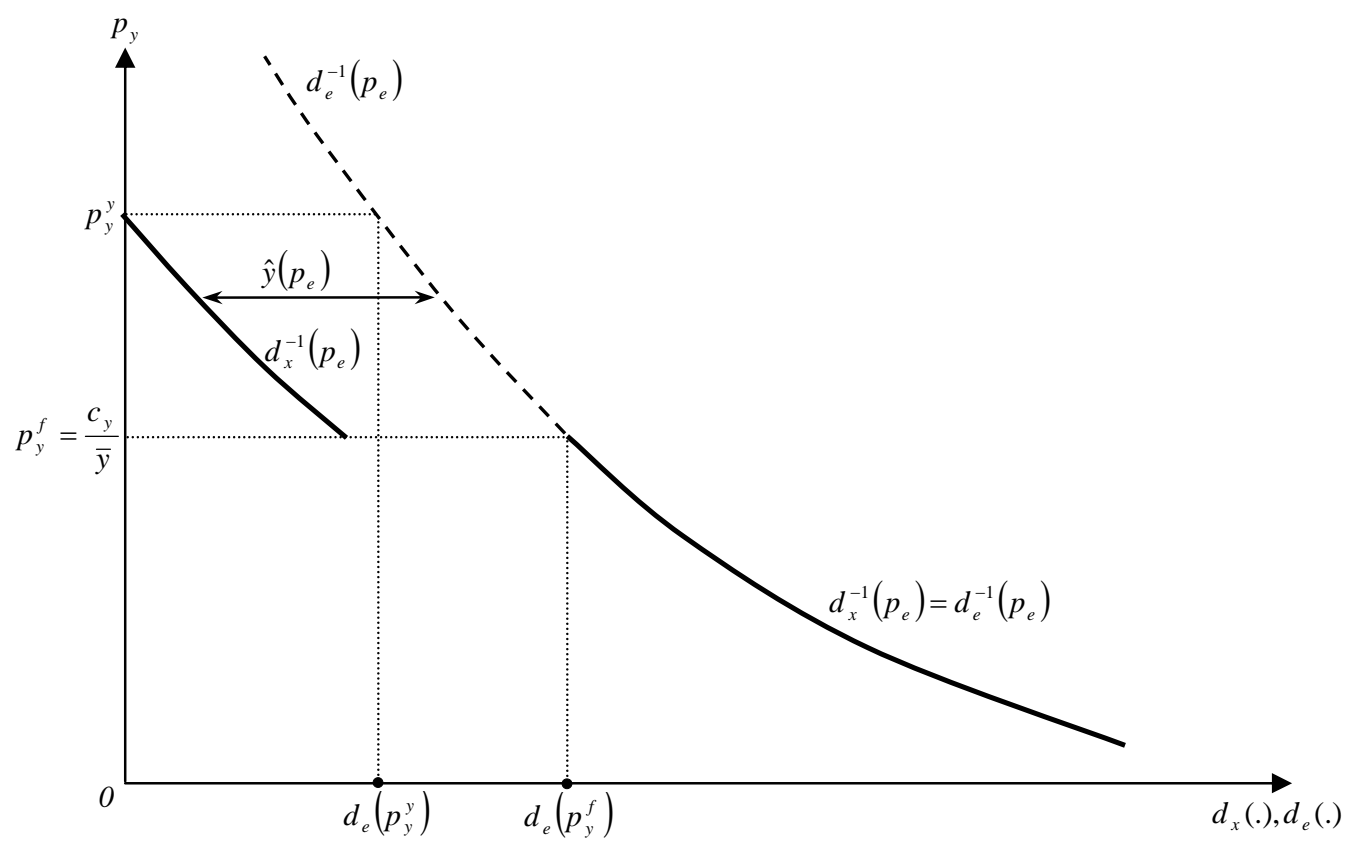

Fig 4. Energy Supply with Abundant Land or Low Demand for Food 


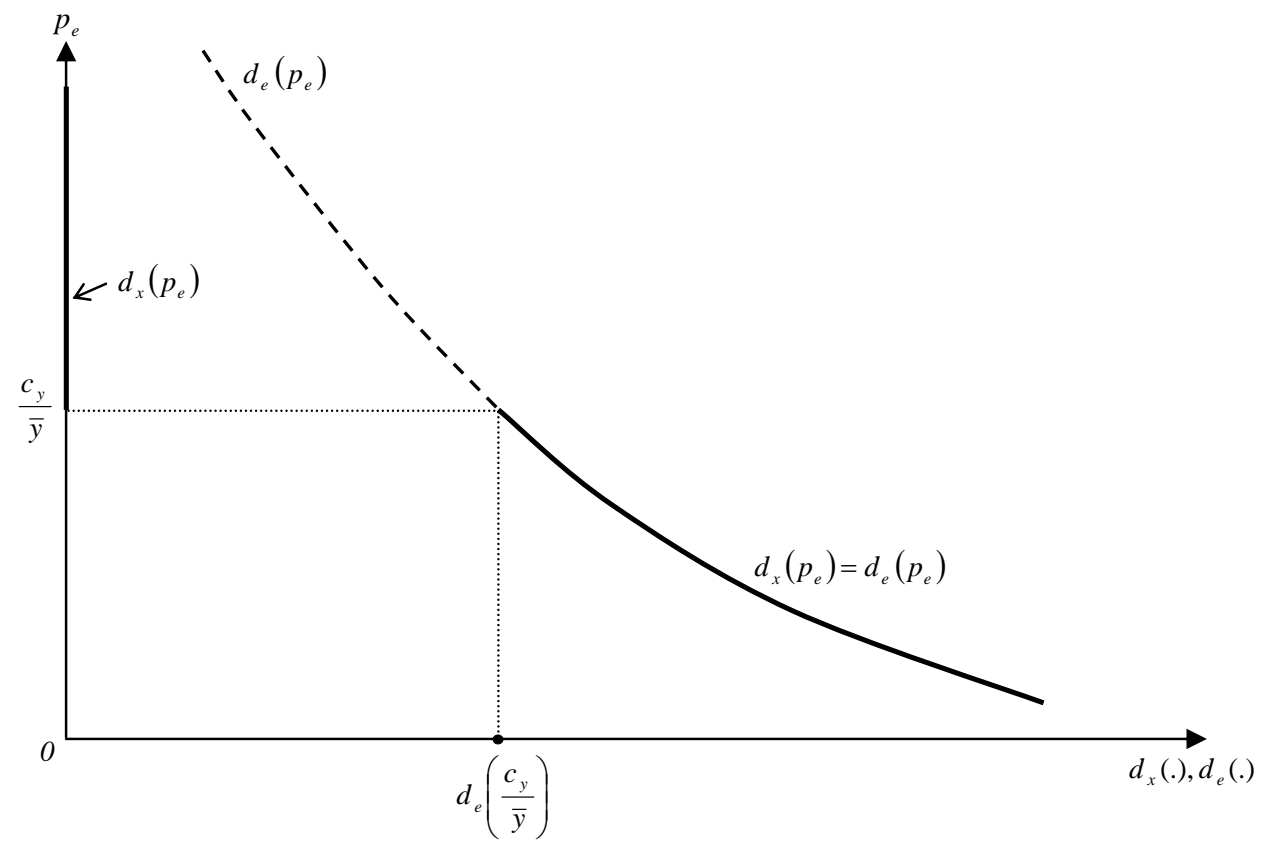

Fig 5. Oil Demand when Land is Abundant or the Demand for Energy is Low

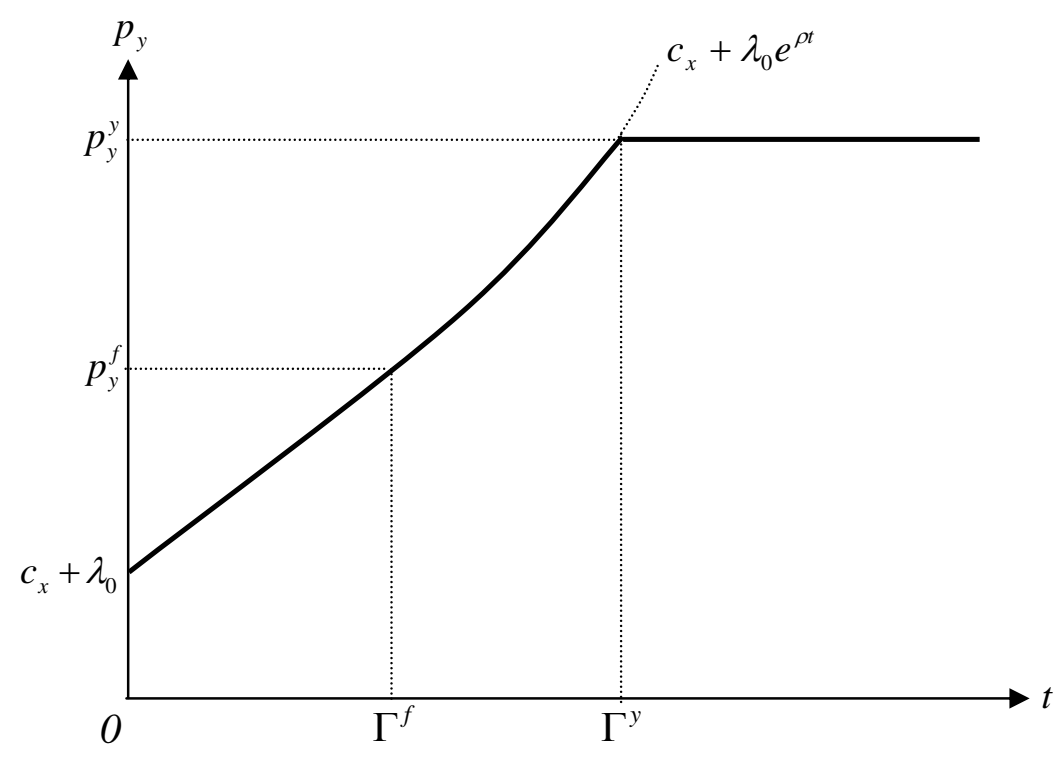

Fig 6. Energy Supply from Land increases monotonically 


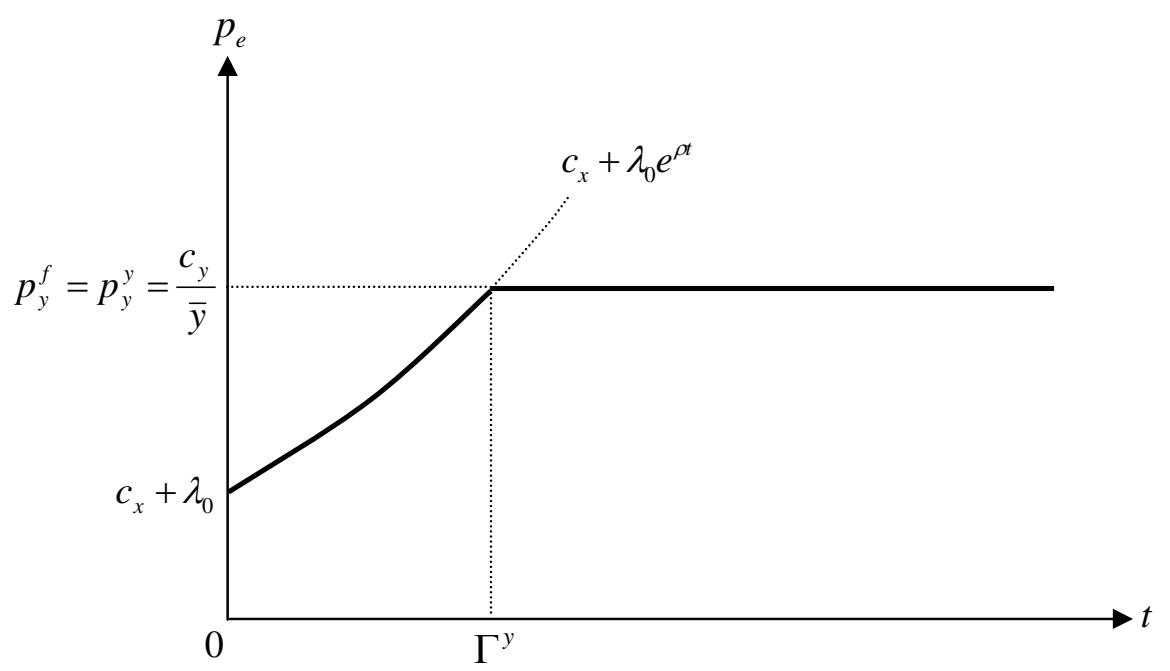

Fig 7. Energy from Land acts as a pure Backstop Resource 


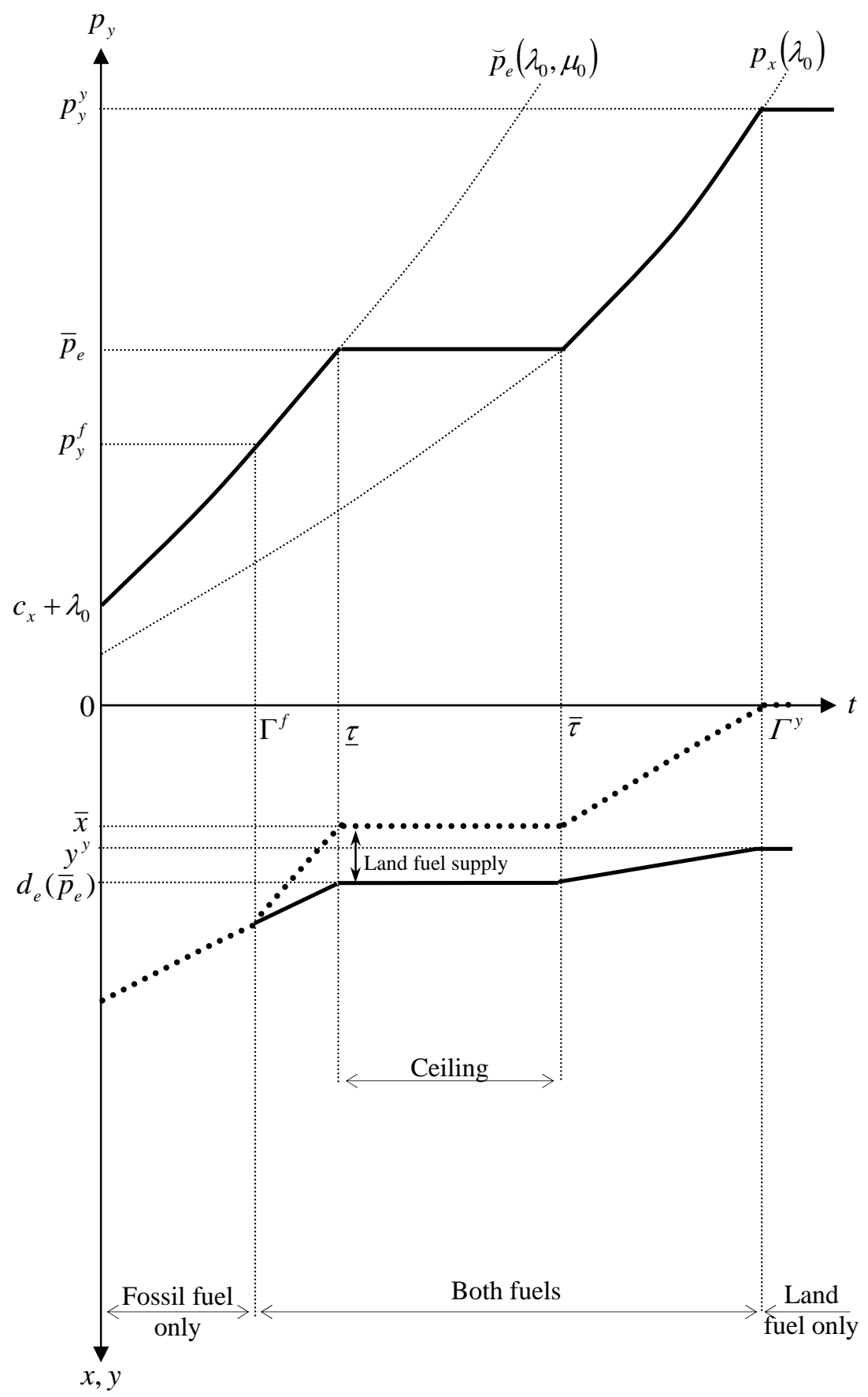

Fig 8. Land Supplies Energy before Regulation Binds 


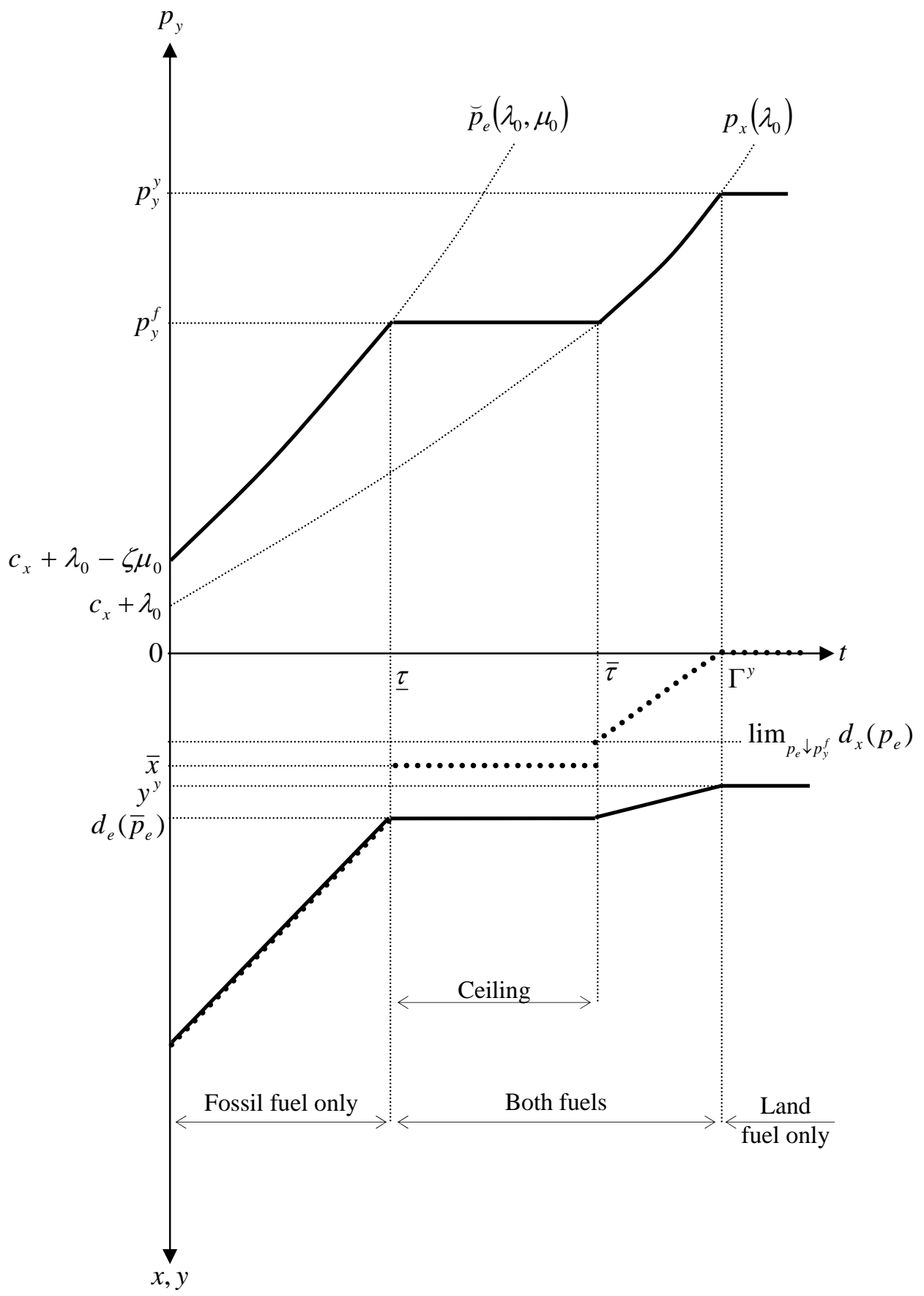

Fig 9. Multiple Discontinuities in the Supply of the Land Fuel 


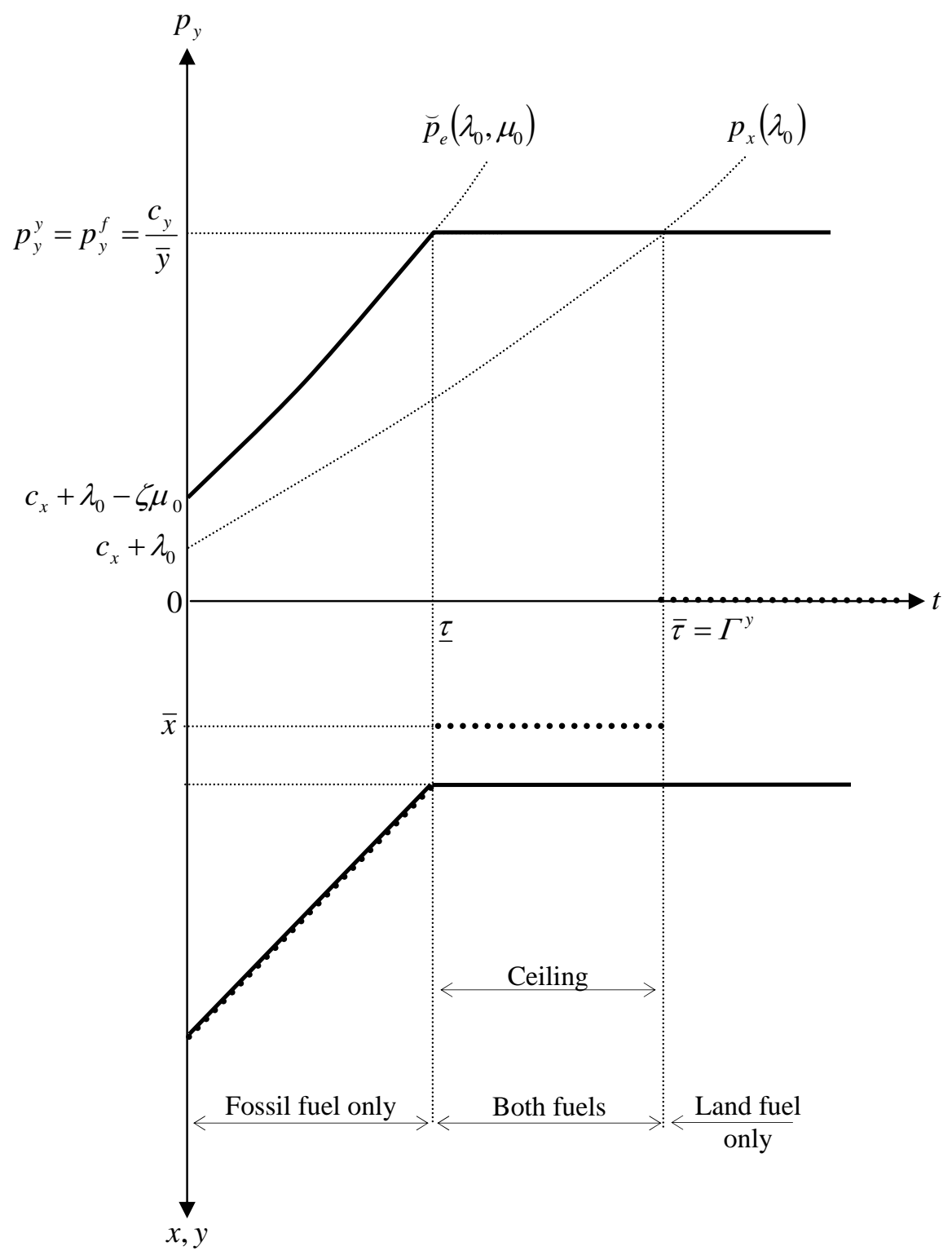

Fig 10. Oil is Exhausted exactly when Regulation ceases to Bind 


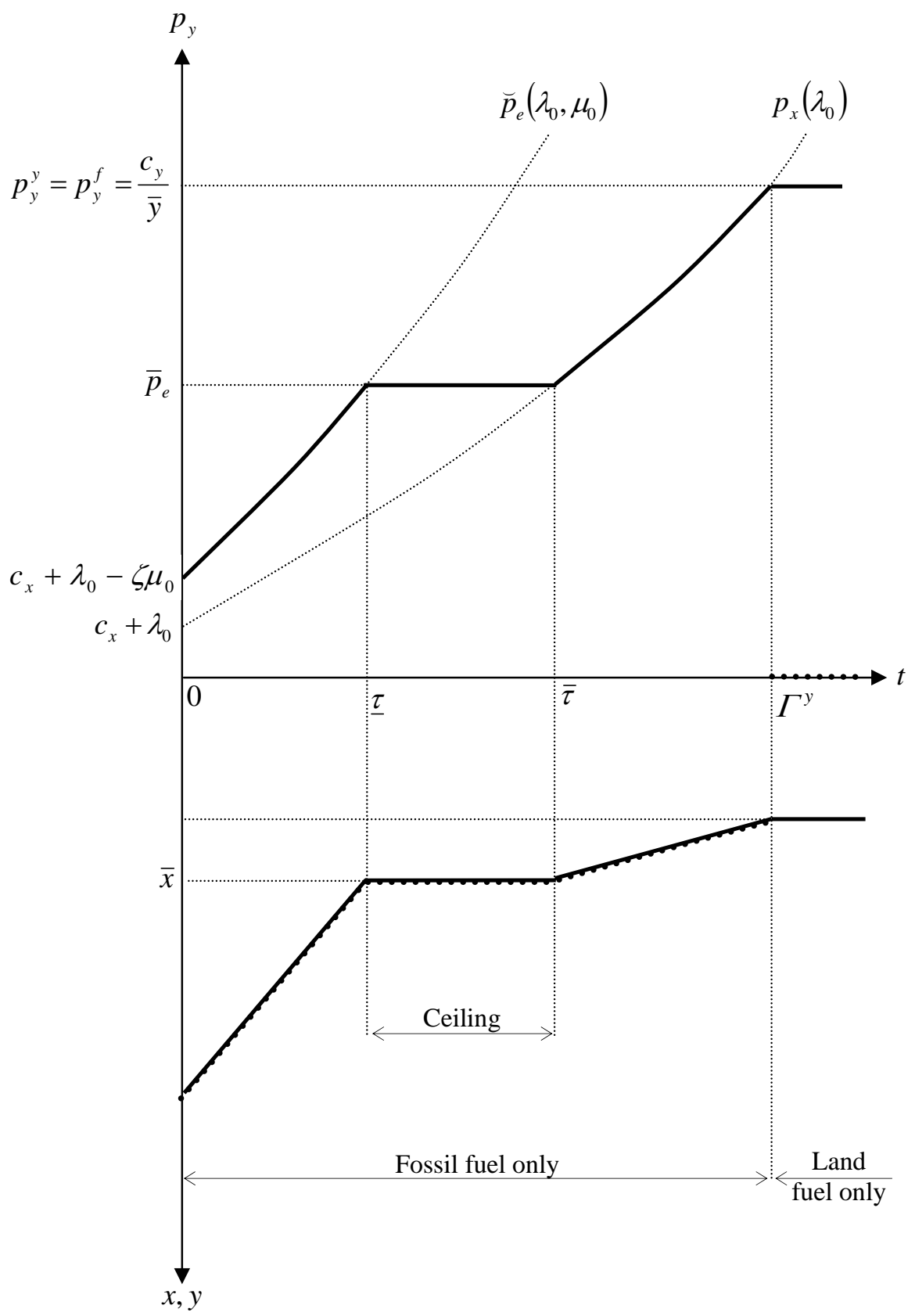

Fig 11. Fuel from Land is expensive: Only Oil is used under Regulation 


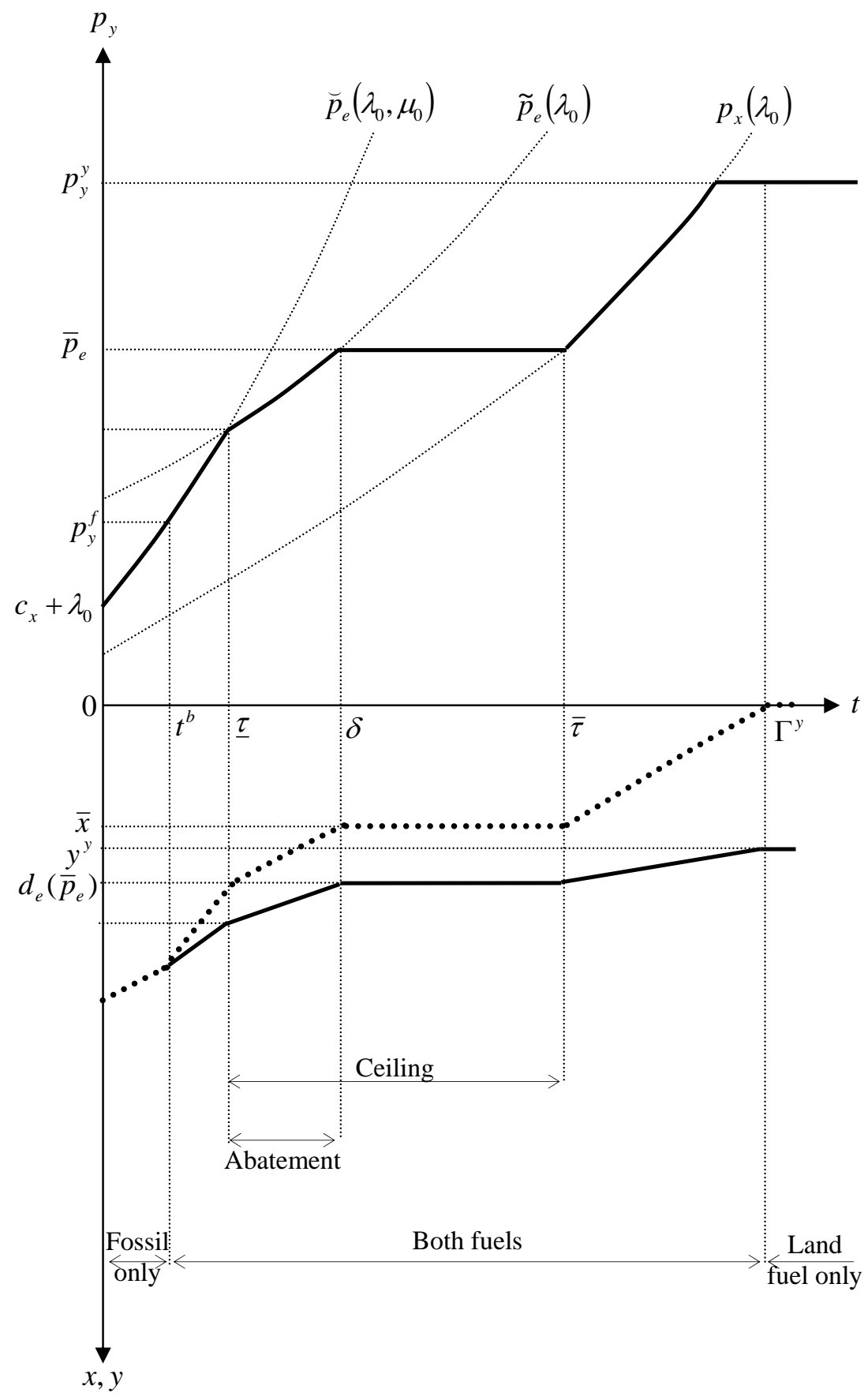

Fig B1. Abatement must start exactly when the Ceiling is achieved, if at all 